\title{
A fossil-calibrated phylogenomic analysis of Daphnia and the Daphniidae
}

\section{Cornetti, Luca}

2019-08

Cornetti , L , Fields , P D , Van Damme , K \& Ebert , D 2019 , ' A fossil-calibrated

phylogenomic analysis of Daphnia and the Daphniidae ' , Molecular Phylogenetics and Evolution , vol. 137 , pp. 250-262 . https://doi.org/10.1016/j.ympev.2019.05.018

http://hdl.handle.net/10138/315200

https://doi.org/10.1016/j.ympev.2019.05.018

cc_by_nc_nd

acceptedVersion

Downloaded from Helda, University of Helsinki institutional repository.

This is an electronic reprint of the original article.

This reprint may differ from the original in pagination and typographic detail.

Please cite the original version. 


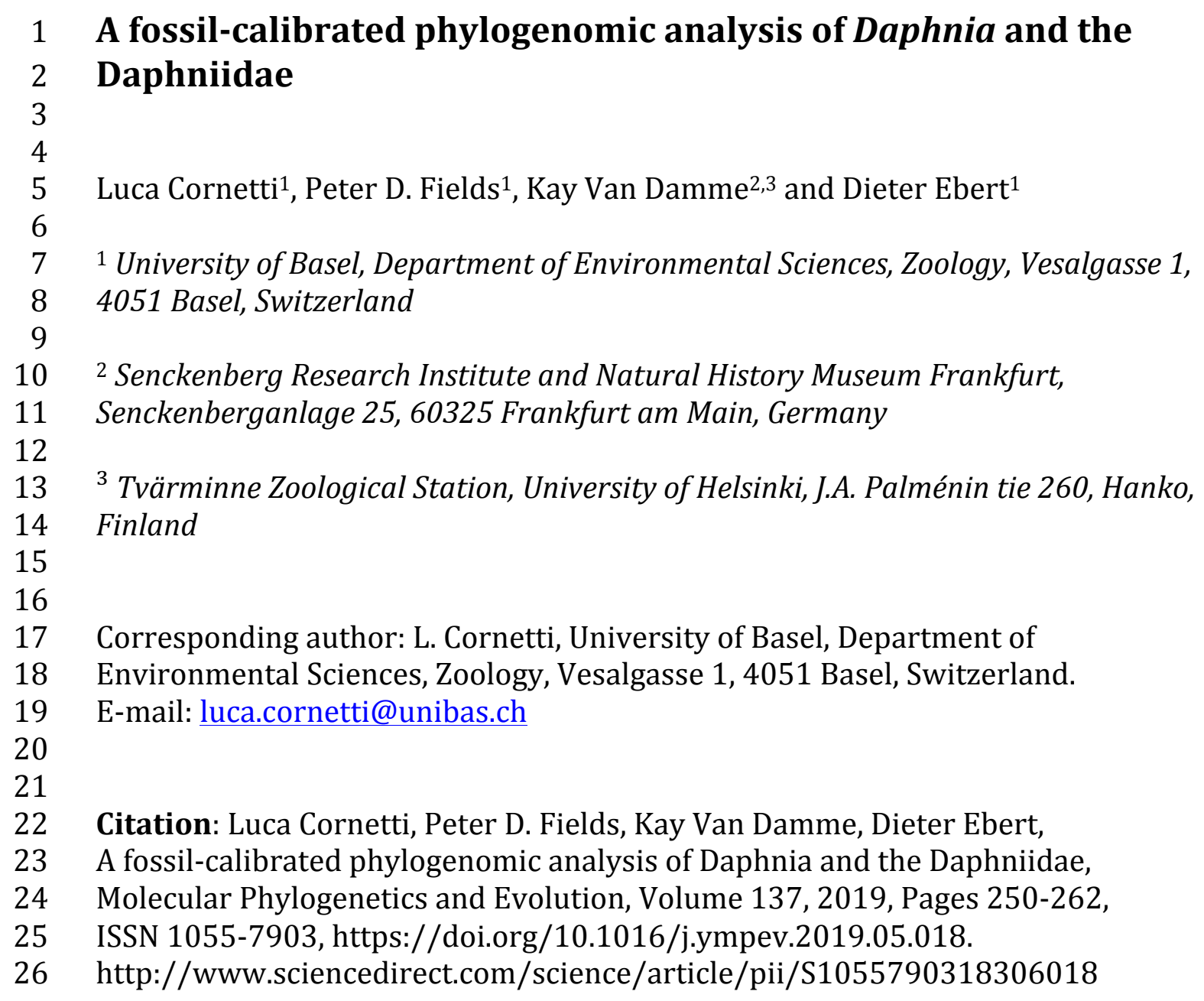




\section{Abstract}

28 In the post-genomic era, much of phylogenetic analyses still relies on mitochondrial

29 DNA, either alone or in combination with few nuclear genes. Although this approach

30 often makes it possible to construct well-supported trees, it is limited because mtDNA

31 describes the history of a single locus, and nuclear phylogenies based on a few loci may

32 be biased, leading to inaccurate tree topologies and biased estimations of species

33 divergence time. In this study, we perform a phylogenomic analysis of the Daphniidae

34 family (Crustacea: Branchiopoda: Anomopoda) including some of the most frequently

35 studied model organisms (Daphnia magna and D. pulex) whose phylogenetic

36 relationships have been based primarily on an assessment of a few mtDNA genes. Using

37 high-throughput sequencing, we were able to assemble 38 whole mitochondrial

38 genomes and draft nuclear genomes for 18 species, including at least one species for

39 each known genus of the family Daphniidae. Here we present phylogenies based on 636

40 nuclear single-copy genes shared among all sampled taxa and based on whole mtDNA

41 genomes. The phylogenies we obtained were highly supported and showed some

42 discrepancies between nuclear and mtDNA based trees at deeper nodes. We also

43 identified a new candidate sister lineage of Daphnia magna. Our time-calibrated

44 genomic trees, which we constructed using both fossil records and substitution rates,

45 yielded very different estimates of branching event times compared to those based on

46 mtDNA. By providing multi-locus, fossil-calibrated trees of the Daphniidae, our study

47 contributes to an improved phylogenetic framework for ecological and evolutionary

48 studies that use water fleas as a model system.

49 Keywords: substitution rates; fossil records; tree discrepancy; gene tree vs species

50 tree; Daphnia magna; Daphnia pulex. 


\section{Introduction}

52 For several decades now, molecular data has allowed researchers to resolve phylogenetic relationships in diverse organisms. However, phylogenies for most taxa are based on a limited number of genes that are usually part of the mitochondrial genome (mtDNA). Although mtDNA has the advantage of being a fastevolving haploid molecule that can help reconstruct well-supported trees, it has substantial limitations, since it only describes the history of a single locus (Galtier et al., 2009). Indeed, discrepancies between individual gene phylogenies and the underlying species tree have been observed (Rubinoff and Holland, 2005). This problem is partially resolved by using nuclear genetic markers; however, selecting only a handful of independent markers from the nuclear genome can mislead researchers about phylogenetic relationships between taxa, and the topologies derived from those genes have often been inconsistent (Salichos and Rokas, 2013). These discrepancies may be caused by biological processes, such as gene duplication, incomplete lineage sorting and horizontal gene transfer via introgression (Maddison, 1997). Also, nuclear genes typically have a limited number of variable characters, which reduces their value for phylogenetic reconstructions. Given the recent rise of high-throughput sequencing techniques, the use of multiple independent loci is now becoming a prerequisite for obtaining robust phylogenies, increasing not only the accuracy of the tree topologies but also the accuracy of species divergence times estimated using molecular dating methods (Zhu et al., 2015).

Species trees can be time-calibrated with fossil records or dated biogeographical events, providing a temporal framework of taxa diversification (Rieux and Balloux, 2016). For those groups of organisms for whom reliable calibration points (i.e., fossil data) are scarce or nonexistent, a common alternative is to calibrate the molecular clock using substitution rates from species that are closely related to the focal group of organisms. This option can also be problematic, however, as the rate of molecular evolution has been shown to vary not only among lineages, but also within individual genomes, and over evolutionary time (Bromham, 2009; Bromham et al., 2018). In addition, using a limited number of markers or, for example, only mitochondrial genes, may yield inaccurate estimates of species divergence time (Arbogast et al., 2002). A well resolved time-calibrated phylogeny is not only a requirement to delimit the taxa and understand the relationships between them, but also provides the necessary baseline for ecological and evolutionary studies.

Certain species of the freshwater crustacean genus Daphnia O.F. Müller, 1785 (Branchiopoda, Cladocera, Anomopoda, Daphniidae) have become important models in ecology and evolution (Lampert, 2011; Stollewerk, 2010), epidemiology (Ebert, 2005), toxicology (Shaw et al., 2008), and, more recently, genomics (Colbourne et al., 2011). However, although these are some of the most frequently studied invertebrates, our understanding of the phylogenetic relationships among Daphnia species still relies mostly on mtDNA genes (cytochrome c oxidase subunit I; COI, 12S and 16S; Adamowicz et al., 2009; Marková et al., 2007; Popova et al., 2016; Schwenk et al., 2000), and divergence times have been estimated with a molecular clock based primarily on one mtDNA gene (reviewed in Van Damme and Kotov, 
2016). The shortcomings of this approach became apparent when, in evaluating the divergence time between $D$. magna and $D$. pulex using eight nuclear genes, Haag et al., (2009) found very different time estimates compared to those based on both fossil records (Kotov and Taylor, 2011) and the mtDNA molecular clock (Colbourne and Hebert, 1996). The nature of such discrepancies may be due to multiple reasons, including the application of unspecific substitution rates, the use of different markers (nuclear vs mtDNA) and the lack of reliable fossil calibrations (Van Damme and Kotov, 2016).

The cladoceran fossil record has recently been revised, so that it now allows minimal time estimates for a few major nodes in the phylogeny of the Daphniidae (Van Damme and Kotov, 2016). Here, we use whole genome sequencing to shed light on the phylogenetic relationships among the Daphniidae in a temporal framework. We performed a phylogenetic study including 18 species from all five genera of the Daphniidae, as well as other anomopod families as outgroups. We focused primarily on the genus Daphnia and, in particular, on species phylogenetically close to D. magna, a keystone aquatic organism, with the aim of identifying its proper outgroup for comparative genomic studies. To date, both $D$. exilis and $D$. similis have been regarded as sister lineages to D. magna (Adamowicz et al., 2009; Colbourne and Hebert, 1996; Orsini et al., 2013), although Popova et al., (2016) has cautioned against assuming sister status on partially resolved phylogenies (Popova et al., 2016). To ascertain sister status definitively, studies must include more taxa and also increase the resolution of the analysis at deeper phylogenetic levels by analyzing multiple genes from the mitochondrial and nuclear genomes. For species within our focal group of taxa in the subgenus Ctenodaphnia (including D. magna and D. similis group), we included samples from wide-spread populations since some of these species have a very wide geographic distribution (Fields et al., 2018; Popova and Kotov, 2013) and it is not always clear how closely they are related.

Although D. magna and D. pulex are model species for the study of ecology and evolutionary processes, building on centuries of research (Lampert, 2011), they represent only a small part of Daphniidae diversity. In this study, we thus include other Daphniidae to provide a broader range of insights on important questions in evolution, ecology, and environmental sciences. For example, the D. longispina species complex has proven to be an excellent system for studying hybridization (e.g. Alric et al., 2016); D. lumholtzi has been widely studied as a successful invasive species in North America (i.e. Engel and Tollrian, 2009), and D. similis has been proposed as an alternative organism to D. magna in ecotoxicological tests (Rodgher et al., 2010). We also include Daphnia species whose remarkable inducible defenses have made them useful in phenotypic plasticity studies (i.e. D. barbata (Herzog et al., 2016); D. atkinsoni (Petrusek et al., 2009); D. carinata (Barry, 2000)). To date, the phylogenetic relationships among these species have been assessed by milestone studies in the field, based, however, on a few mitochondrial genes (Adamowicz et al., 2009, 2004; Crease et al., 2012; Petrusek et al., 2008; Popova et al., 2016; Taylor et al., 1996). We extend these studies, here, to the whole genome level. Furthermore, we incorporate all five Daphniidae genera, including the genus Megafenestra, which 
141 had not been included in earlier studies (i.e. deWaard et al., 2006; Richter et al.,

142 2007). This genus is important to include, since at least two genera of each

143 subfamily sensu Dumont and Pensaert (Dumont and Pensaert, 1983) (Daphniinae:

144 Daphnia, Ceriodaphnia, Simocephalus; Scapholeberinae: Megafenestra,

145 Scapholeberis) are necessary to clarify the relationships in the family. Additionally,

146 the proper identification of sister clades as choices of outgroups is crucial for

147 comparative genomic studies (Rota-Stabelli and Telford, 2008) and is therefore a

148 further aim of our study. Former phylogenetic studies at the systematic level of

149 order to classes that included Daphniidae may suggest that any non-Daphnia genus

150 could be the sister clade to Daphnia (Abele and Spears, 2000; deWaard et al., 2006;

151 Richter et al., 2007; Stenderup et al., 2006; Swain and Taylor, 2003; Van Damme et

152 al., 2007).

153 For the 18 species included here, we newly sequenced and assembled the

154

155

156

157

158

159

160

161

162

163

164

165

166

167

168

169

170

171

172

173

174

175

176

177

178

179

180

181

182

183

184

185 entire mtDNA and nuclear genomes and used a multi-locus species tree to build a robust molecular phylogeny. We time calibrated these phylogenies using: (i) all the fossil records available for Anomopoda and (ii) mtDNA and nuclear substitution rates obtained from mutation-accumulation studies in D. pulex (Keith et al., 2016; Xu et al., 2012). We then compared time calibrated phylogenies obtained with different approaches and markers and discussed their similarities and discrepancies. By providing multi-locus, fossil-calibrated trees of Daphniidae, our study provides a robust phylogenetic framework for ecological and evolutionary studies that involve water fleas of the genus Daphnia.

\section{Materials and Methods}

\subsection{Samples and Genomic DNA Extraction}

Cladocera are cyclical parthenogens and can be maintained as stable genotypes (clones) under lab conditions in an asexual mode of reproduction. These clonal cultures produce sufficient material for genome sequencing. We analyzed the mitochondrial and nuclear genomes of 40 clones of the family Daphniidae and, as outgroups, one clone of Moina brachiata (family Moinidae) and one of Bosmina cf. longispina maritima (B. coregoni-group) (family Bosminidae). Both families of the Aradopoda (Daphniidae and Moinidae) are represented and, within the Daphniidae, taxa from all genera of the two subfamilies are included: the Daphniinae (Ceriodaphnia, Daphnia, Simocephalus) and the Scapholeberinae (Megafenestra, Scapholeberis).

Within Daphnia, we analyzed 14 different taxa belonging to the two subgenera, Daphnia (including D. pulex group and D. longispina group) and Ctenodaphnia (Table 1). Since one focus of the study is to provide a comparative phylogenomic frame for D. magna, being the most studied cladoceran, the taxon coverage in Ctenodaphnia (ten species) is higher than for the subgenus Daphnia (four species). While the dataset here represents a fraction of the diversity in the genus, ca. 90 valid taxa and many more with unresolved taxonomy (Kotov, 2015), it covers representatives of major species groups and includes three of the four major branches in Ctenodaphnia retrieved by Adamowicz et al. (2009). D. ephemeralis, which forms a separate lineage in the latter study, was not included here. 
We also included Daphnia clones whose genomic resources were already available in sequence databases: two clones of the $D$. pulex complex belonging to different lineages, TCO (Colbourne et al., 2011) and PA42 (Ye et al., 2017), one $D$. magna clone (XINB3, Daphnia Genome Consortium) that was analyzed for both the mitochondrial and nuclear genomes, and one clone of the D. obtusa complex (Tucker et al., 2013) for which we were able to assemble only the mitochondrial genome. The cladoceran clones sequenced for this study were obtained from parthenogenetic females collected in the field, or were hatched from resting eggs collected in the field. Isofemale lines were produced by keeping individual females in isolation and allowing them to reproduce only asexually.

To reduce bacterial DNA, all animals were kept for three days in a solution of Ampicillin, Streptomycin and Tetracycline (Sigma) at a concentration of $50 \mathrm{mg} / \mathrm{L}$ each, and transferred daily into a fresh antibiotic solution before their DNA were extracted. To reduce gut content, the animals were also not fed during this three-day treatment, instead receiving $5 \mathrm{mg}$ of superfine beads of the gel filtration resin Sephadex ${ }^{\circledR}$ G-25 (Sigma-Aldrich) twice a day in their medium. For smaller species (less than $1 \mathrm{~mm}$ body size), bentonite clay (Bentonite MED) at a concentration of $50 \mathrm{mg} / \mathrm{L}$ was added daily to the medium. Sephadex and bentonite clay cause gut evacuation when ingested by the animals. We extracted DNA from 30-100 animals of each clone. Genomic DNA was extracted using the QIAGEN Gentra Puregene Tissue Kit, including the RNaseA (100 mg/ml; Sigma) digestion step. Whole-genome Illumina paired-end sequencing (read length $125 \mathrm{bp}$ ) was performed by the Genomics Facility service platform at the Department of Biosystem Science and Engineering (D-BSSE, ETH) in Basel, Switzerland, on an IlluminaHiSeq 2500.

\subsection{Mitochondrial Genome Assemblies and Mitochondrial Datasets}

After removing Illumina adapters from the raw reads using Trimmomatic version 0.35 (Bolger et al., 2014), the mitochondrial genomes were assembled. For each clone, a subset of two million randomly selected reads were used as input for the MITObim package (Hahn et al., 2013). MITObim employs a baiting and iteration mapping approach, implemented in the MIRAbait module of the MIRA assembler (Chevreux et al., 1999). The mitochondrial genome derived from the D. magna XINB3 individual genome (V2.4; Daphnia Genome Consortium) was used as a reference. This procedure was repeated four times for each clone, using a different subset of two million reads each time. To assess the consistency of the mitochondrial genome assemblies, the four individual sequences were aligned using MUSCLE v3.8.31 (Edgar, 2004) and visually checked for discrepancies. In the rare instances where discrepancies were found, the haplotype supported by the highest number of sequences was considered for further analyses.

We annotated the mitochondrial genomes independently using the MITOS web server (Bernt et al., 2013), which allowed us to identify the thirteen protein coding genes and the two structural rRNA genes. These genes were individually aligned with MUSCLE v3.8.31 (Edgar, 2004) and concatenated into a data matrix using the software Sequence Matrix (Vaidya et al., 2011) and keeping the information about the gene partitioning (i.e. the start and end positions for each 
231 protein coding gene in the big data matrix). We prepared and separately analyzed three different datasets that consisted of (i) the concatenation of the thirteen protein coding genes (PCGs) and the two structural rRNA genes, (ii) the concatenation of only the thirteen protein coding genes, and (iii) the amino acid sequences of the thirteen protein coding genes. Because amino acid sequences are sometimes preferred in recovering deep phylogenetic relationships(Simmons et al., 2002), we included this dataset, even though several studies have shown that nucleotide sequences outperformed amino acid sequences also for the resolution of deep nodes (Simmons, 2017; Simmons et al., 2004).

To compare our data with previously published phylogenies, we aligned our nucleotide sequences first with those used by Adamowicz et al., (2009), analyzing the concatenation of $16 \mathrm{~S}, 12 \mathrm{~S}$ and COI mtDNA genes, but focusing only on taxa without missing data. We also aligned them with the nucleotide sequences used by Popova et al., (2016), but analyzed 12S and COI independently, since in the original article, different taxa were sequenced for these two mtDNA genes.

\subsection{Nuclear Genome Assemblies}

MaSuRCA (Zimin et al., 2013) was used to assemble the nuclear genome of each cladoceran clone. This method relies on the computational efficiency of the de Brujin graph methods combined with the flexibility of overlap-based assembly strategies. The Illumina paired-end reads were used as input for MaSuRCA and were assembled into super-reads. The assembly procedure was repeated three times for each clone, using the default settings but varying the kmer size (GRAPH_KMER_SIZE $=55,65$ and 75 were tested). The assembly statistics (number of scaffolds, N50, maximum scaffold length and total assembly length) were evaluated with ABySS 2.0.2 (Jackman et al., 2017). The resulting assembly containing the lowest number of scaffolds and expected genome length was considered the optimal assembly for our purposes and used for downstream analyses.

\subsection{Ortholog Identification, Alignment and Nuclear Datasets}

The nuclear genome assemblies were assessed for biological completeness using BUSCOv3 (Waterhouse et al., 2017). A total of 1,066 single-copy arthropod genes were searched against each individual assembly. The single-copy genes identified by the BUSCO approach as "complete" (i.e. without any in-frame stop-codon) were used to define ortholog groups across the cladoceran genomes and to build phylogenetic trees.

To obtain the high-confidence sequence alignments required for accurate phylogenetic analysis, especially when divergence time among taxa is relatively old (Kumar and Filipski, 2007), we computed the alignments with the software TranslatorX (Abascal et al., 2010). For each protein coding gene, the alignment, performed with MUSCLE v3.8.31 (Edgar, 2004), was guided by the corresponding deduced open reading frame. Ambiguously aligned positions were removed using Gblocks v.0.91b (Castresana, 2000), so that there were no gaps in the final alignments. Single gene alignments were concatenated with Sequence Matrix 
(Vaidya et al., 2011). For the nuclear genome, we prepared and separately analyzed three different datasets consisting of (i) the concatenation of orthologs, (ii) the concatenation of the four-fold degenerate sites of the orthologs, and (iii) the amino acid sequences of the orthologs. As mentioned above, the analysis of nucleotide and amino acid datasets allowed us to compare their performances, especially in the resolution of deep phylogenetic relationships. The rationale behind analyzing the four-fold degenerate sites is that such sites are nucleotide positions where all changes are synonymous and assumed to be neutrally evolving; as such, they are well-suited for phylogenetic reconstruction and for estimating species divergence time (Edwards, 2009).

\subsection{Maximum-likelihood Phylogenetic Inference and Tree Comparison} Maximum-likelihood phylogenies for all the mitochondrial and nuclear datasets were obtained using the software RAxML v.8.1.20 (Stamatakis, 2014). The best ML trees were inferred as follows: 1) assuming a General Time Reversal (GTR) model of sequence evolution with a gamma-distribution model of rate heterogeneity for nucleotide sequences, and 2) using the automatic selection of protein sequence evolution (PROTGAMMAAUTO) for amino acid sequences, always taking into account gene partitioning. One hundred pseudo-replicates were generated by applying a bootstrap approach to test the reliability of the best trees. Using the same setting as above, we inferred ML trees for each independent mitochondrial and nuclear gene. In addition to the concatenated analysis, we also estimated species trees with ASTRAL-III v5.6.3 (Zhang et al., 2018), which uses quartet frequencies found in gene trees and has shown to be accurate also in the presence of incomplete lineage sorting (e.g. Davidson et al., 2015). We ran ASTRAL using default settings and individual nuclear gene trees (obtained from both nucleotide and amino acid sequences) as input.

We used Densitree 2.2.5 to visualize phylogenetic discrepancies between single gene trees of the nuclear genome (Bouckaert, 2010). We made the best nucleotide ML tree of each gene ultrametric, using the function chronos in the R package APE (Paradis et al., 2004) and then plotted them. We also quantitatively evaluated the discrepancies between the single mitochondrial gene trees, that were reconstructed excluding $D$. cf. obtusa, which was missing in the nuclear matrix, and the best ML nuclear phylogeny using Ktreedist (Soria-Carrasco et al., 2007), which measures the differences in the relative branch length and topology between phylogenetic trees.

\subsection{Bayesian Estimate of Species Divergence Time}

We applied BEAST 2.4.5 (Bouckaert et al., 2014) to estimate the ages and confidence intervals of branching events using two independent approaches. In the first approach, we included in the phylogeny all relevant and available fossil records for Anomopoda as calibration priors. Our calibrations were based on the following argumentation: The oldest unambiguous Cladocera fossils are from Mesozoic times, in the Early Jurassic (174 -201Mya; Kotov, 2007; Van Damme and Kotov, 2016), and the first fossils of the order Anomopoda date to the end of the Jurassic 
321 (Jurassic/Cretaceous boundary; 145Mya; Kotov and Taylor, 2011). It is likely,

322 therefore, that the Anomopoda ancestor and the divergence of the two suborders,

323 Aradopoda and Radopoda (Dumont and Silva-Briano, 1998; Kotov, 2013), occurred

324 well before the Jurassic age, and even before the Mesozoic era, though there is no

325 fossil evidence (Van Damme and Kotov, 2016).

326

327

328

329

330

331

332

333

334

335

336

337

338

339

340

341

342

343

344

345

346

347

348

349

350

351

352

353

354

355

356

357

358

359

360

361

362

363

364

365

For our analysis, we used a uniform prior on the root describing the most recent common ancestor (MRCA) of all Anomopoda-in our case the split between the Radopoda, represented by the Bosminidae and the Aradopoda, which include Daphniidae and Moinidae-and placed it at the most recent divergence time suggested by fossil evidence-the Late Jurassic (145-163.5 Mya). Although the split Bosminidae/Aradopoda is likely to be older, we consider the Late Jurassic prior on the root the most conservative and reliable prior substantiated by fossil evidence in describing the MRCA of all Anomopoda. We used four additional Log-normal priors derived from fossil evidence as reported in Van Damme and Kotov (2016): one describing the Moinidae-Daphniidae split (at least 145 Mya, coded in BEAUti as M=2, $S=1.25$, offset=145, which translates into median 152 Mya, 95\%CI 146-203 Mya); the second describing the Simocephalus-Daphnia split (at least 145 Mya); a third describing the Ceriodaphnia-Daphnia split (at least 118 Mya, coded in BEAUti as $\mathrm{M}=2, \mathrm{~S}=1.25$, offset=118, which translates into median $125 \mathrm{Mya}, 95 \% \mathrm{CI}$ 119-176 Mya), and finally, the subgenus Ctenodaphnia- Daphnia split (at least $145 \mathrm{Mya}$ ). We specified constraints of monophyly for all fossil calibrated nodes; this ensured, for example, that the Moinidae-Daphniidae split must have occurred earlier than the Ctenodaphnia-Daphnia split.

As the origin of the Anomopoda likely pre-dates the Late Jurassic, and several extant families may have been established even before the Mesozoic (Van Damme and Kotov, 2016), we explored the timing of the nodes by estimating the MRCA of the Anomopoda at two earlier hypothetical dates: one in the Early Jurassic, the appearance of first Cladocera fossils, 174-201 Mya (Kotov, 2007), and another in the Permian, a Paleozoic estimate, when Cladoceromorpha fossils of the order Cyclestherida first appeared, about 252-299 Mya (Raymond, 1946; Sun et al., 2016). In BEAUti, we set trees and site models as linked for the mtDNA concatenated phylogeny based on the results of site JModelTest 2 (Darriba et al., 2012). All partitions, in fact, resulted in the same substitution model (GTR + GAMMA + Invariant sites). We specified unlinked clock models, allowing partition-specific estimates of substitution rates using a strict clock.

For the nuclear analyses, an unpartitioned alignment of four-fold degenerate sites was used with a "GTR + GAMMA + Invariant sites" substitution model. Computational constraints did not allow us to analyze a partitioned dataset of hundreds of orthologs in BEAST. The concatenation of four-fold degenerate sites of the identified orthologs was used to estimate a genome-wide substitution rate, while the fossil priors were used to calibrate the molecular clock. The BEAST analyses were run with a MCMC chain length of 10,000,000, after discarding the first $10 \%$ of iterations as burn-in, and parameter sampling every 1,000 generations. We examined the log files with Tracer v1.6 (Rambaut et al., 2014) to evaluate the convergence of the analysis and to ensure that the effective sample size (ESS) of the 
parameters was greater than 200 .

In our second approach, we estimated sequence divergence time using a strict molecular clock based on the neutral substitution rates derived from mutation-accumulation experiments in sexual lines of $D$. pulex. Substitution rates of $2.0 \times 10^{-8}$ per nucleotide per generation (Xu et al., 2012) and $4.33 \times 10^{-9}$ (Keith et al., 2016) per nucleotide per generation were used for the mitochondrial and nuclear phylogeny, respectively. As Daphnia undergoes sexual reproduction about once per year (Lampert, 2011), we used this rate to test time-based estimates (Mya).

\section{Results}

\subsection{Mitochondrial Phylogenies}

We found no inconsistencies between the four individually assembled genome sequences for each clone. The sequences of all genes (PCGs and rRNA) could be unambiguously aligned (ENA study number ERP109988, project: PRJEB27855, accession numbers: LS991483-LS991524). The best ML trees obtained with the three different mtDNA datasets had identical topologies (Fig. 1). The dataset consisting of all PCGs and the two structural rRNA genes was the most highly supported (an average bootstrap value > 92), although all three phylogenies showed high bootstrap values. The mtDNA amino acid dataset showed the lowest topological support (average bootstrap value of 86.7), with bootstrap values similar to the nucleotide datasets for deep nodes. Our results confirmed the subgenera Daphnia and Ctenodaphnia as significantly supported monophyletic groups. D. longispina, the only representative in our study of this widely studied species group, appeared to be a sister taxon to the D. pulex/D. obtusa groups.

Within the subgenus Ctenodaphnia, we observed that the Australian D. cf. carinata was sister lineage to the $D$. similis/D. sinensis/D. lumholtzi clade. In such clade, the three species constitute clearly distinct groups with little differentiation after an initial branching off by D. lumholtzi. In D. magna, we observed the split between Western Eurasia and East Asian (and North American) lineages that Fields et al. (2018) and Bekker et al., (2018) previously reported. The mtDNA phylogeny also showed some unexpected results. We found that $D$. cf. "similis" appeared to be a sister taxon to D. magna. D. cf. "similis" does not cluster with other species of the $D$. similis group. In fact, this unnamed taxon from Canada likely belongs to the $D$. exilis group (Adamowicz et al., 2009; Popova et al., 2016). We found that D. hispanica clusters with D. atkinsoni (Fig. 1) and does not appear close to D. barbata. Indeed, the bootstrap values for $D$. hispanica appearing near $D$. barbata in a previous mtDNA phylogeny had low support (Adamowicz et al., 2009).

The same pattern was confirmed when we analyzed the concatenation of the mtDNA genes 16S, $12 \mathrm{~S}$ and COI of the taxa in our study compared with the taxa in Adamowicz et al., (2009) (Supplementary Fig. S1). Our best 16S/12S/COI ML tree was poorly supported, especially for the majority of internal nodes (Supplementary Fig. S1). We also compared our sequences with those published by Popova et al., (2016), which confirmed that our populations of "true" D. similis form a monophyletic clade when analyzed simultaneously with populations from Israel, Russia and several European locations (bootstrap values of 100 and 97, for $12 \mathrm{~S}$ and 
411 COI respectively, Figures S2 and S3). These populations contain several clones from the vicinity of the type locality of $D$. similis in Israel. Clones of $D$. cf "similis" from the

413 Nearctic analyzed here are genetically very similar, or in some cases identical, to the 414 D. cf. "similis" clones analyzed for COI gene in (Popova et al., 2016)(Supplementary

415 Fig. S3). Since we never observed monophyly with $D$. similis, and found a sequence dissimilarity of about 12 and $18 \%$ for $12 \mathrm{~S}$ and COI, respectively, against $D$. similis, our mtDNA data indicate that $D$. cf. "similis" represents a different species from $D$. similis. This confirms earlier observations; in fact, the New World D. cf. "similis" belongs to the D. exilis-group instead (Adamowicz et al., 2009; Popova et al., 2016).

\subsection{Nuclear Phylogenies}

We obtained a draft nuclear genome assembly for each of the 38 cladoceran clones sequenced for this study. The quality of the genome assemblies varied substantially as assessed by scaffold number constituting the assembly (Table S1). However, the genome assessment performed with BUSCO retrieved the great majority of complete single-copy arthropod genes (on average about $94 \%$, Supplementary Fig. S4). These genes were used to build a matrix for genome-wide nuclear phylogenetic analyses. After removing ambiguously aligned positions and allowing no gaps in the final alignments, we obtained a set of 636 orthologs, with only $4 \%$ missing data. The average gene length was about 800 bp (range 138 to 3366 bp, ENA study number ERP109988, project: PRJEB27855, accession numbers: LR000001-LR025064).

The best ML trees obtained from the three concatenated nuclear datasets had almost identical topologies. The two nucleotide trees were identical (Fig. 2), while the amino acid tree showed some variations in the relationships of non-Daphnia taxa. More specifically, Scapholeberis formed a separate branch (nucleotide trees) or grouped together with Megafenestra and Simocephalus (amino acid tree; Supplementary Fig. S5). All three phylogenies were highly supported, showing bootstrap values of 100 in almost all internal nodes. A bootstrap value of 90 was observed in the amino acid tree at the branching of non-Daphnia species (Supplementary Fig. S5). The ASTRAL species trees obtained with nucleotide and amino acid sequences were identical and in complete agreement with the ML topology resulting from the concatenated amino acid sequences (Supplementary Fig. S5). Local posterior probabilities were high across the ASTRAL species trees, with only one internal node with posterior probability less than 1.0. Such node describes the phylogenetic relationships among non-Daphnia genera (Figure 2, Supplementary Fig. S5). Throughout most of the tree, the nuclear (nucleotide) topology resembled the mtDNA phylogeny, showing dissimilarities only in the position of the non-Daphnia taxa. The mtDNA tree showed both Simocephalus and Ceriodaphnia as the sister taxa to Daphnia, whereas the nuclear tree showed only Ceriodaphnia as a Daphnia sister clade. Also the nuclear phylogeny showed Scapholeberis (which groups with Megafenestra, the other representative of the subfamily Scapholeberinae in the mtDNA tree), as the first Daphniidae branching off and as sister to all other Daphniidae. Additionally, in the nuclear trees, Megafenestra and Simocephalus always cluster together (Fig. 2, Supplementary Fig. S5). 
We performed two types of tree comparisons for the mitochondrial and nuclear genomes. First, we graphically compared the topologies obtained from each single nuclear gene. Second, we quantitatively assessed the discordance between individual mtDNA gene trees and the species tree, considering the topology of the ML nuclear phylogeny as being the most reliable in describing the relationships within the Daphniidae.

The DensiTree plot shows that, overall, there is a marked discrepancy among gene tree topologies at the nuclear level (Fig. 3). In fact, after drawing all the single gene trees, some densely colored areas become apparent, especially in correspondence with external nodes where many trees agree on the topology and branch length. There were also, however, places in the plot where webs of lines are visible, for example in the relationships among taxa of the subgenus Ctenodaphnia, indicating low levels of concordance among gene trees (Fig. 3).

We also observed a remarkable discordance between individual mtDNA gene trees and the species tree, with K-scores varying from 0.40 for $12 \mathrm{~S}$ to 0.67 for atp8. Interestingly, $\mathrm{COI}$, a gene included in several phylogenetic, taxonomical and molecular studies concerning Daphnia (Adamowicz et al., 2009; Petrusek et al., 2008; Popova et al., 2016), shows one of the highest K-scores (0.60, Table S2), suggesting a strong discrepancy between the COI gene tree and the species tree based on nuclear genes.

\subsection{Divergence Time Estimation}

We performed divergence time estimation for the mtDNA and nuclear phylogenies independently, using both fossil record information and substitution rates. In all cases, we observed high ESSs ( $>200$ ) for the parameters. Our assessment with Tracer also showed that all the analyses had converged. To directly compare the resulting time-calibrated phylogenies, we selected six relevant nodes: the MRCA of Daphnia-Ctenodaphnia; the MRCA of the D. longispina - D. pulex group; the MRCA of $D$. magna and the D. similis group (D. similis-sinensis-lumholtzi); the MRCA of $D$. magna/D. cf "similis"; the MRCA of D. similis/D. sinensis; and the MRCA D. magna (Europe)/D. magna (Asia) (Table 2). Table 2 summarizes the divergence times observed in our analyses. We base the following comparisons on estimates obtained using a uniform prior that places the MRCA of all Anomopoda in the Late Jurassic period (145-163.5 Mya), the most conservative estimate supported by fossil data. The latter resulted in the youngest age in comparison to when the MRCA of all anomopods was hypothetically dated, at least in the Early Jurassic or in the Permian, though there is no fossil evidence (see Table 2).

The time-dated mtDNA datasets with fossil records and substitution rates led to very different estimates of branching events. For example, the MRCA of the subgenera Daphnia-Ctenodaphnia was dated 145.2 Mya (95\%HPD: 145.0-145.5) when fossil priors were included; however, the same node was dated 26.9 Mya (26.1-27.8) using a fixed substitution rate (Table 2). This latter estimate obtained with substitution rates must be considered as unfounded, however, as the fossil record confirms that the two subgenera, Daphnia-Ctenodaphnia, already co-existed at least 
501

502

503

504

505

506

507

508

509

510

511

512

513

514

515

516

517

518

519

520

521

522

523

524

525

526

527

528

529

530

531

532

533

534

535

536

537

538

539

540

541

542

543

544

545

145 Mya (Kotov and Taylor, 2011). In line with these marked discrepancies, the estimated substitution rates obtained for single mtDNA genes ranged between 2.36 $\times 10^{-9}(12 \mathrm{~S})$ and $6.18 \times 10^{-9}$ (atp8). This was, on average $\left(4.12 \times 10^{-9}\right.$, Table S3), about one order of magnitude slower that what was documented $\left(2.0 \times 10^{-8}\right)$ for $D$. pulex (Xu et al., 2012). When we used the two earlier, hypothetical priors on the root, we observed a similar pattern (Early Jurassic: between $2.14 \times 10^{-9}$ to $5.68 \times 10^{9}$, average: $3.76 \times 10^{-9}$, Table S4; Permian: between $1.74 \times 10^{-9}$ to $4.63 \times 10^{-9}$, average: $3.07 \times 10^{-9}$, Table S5).

The marked variation in time estimates for branching events that we observed in the mtDNA analyses are not as evident in terms of discrepancy in time estimates between methods as they are for the genome-wide nuclear phylogenies. Here, the MRCA of the sub-genera Daphnia-Ctenodaphnia was dated 145 Mya (95 \%HPD: 145.0-145.1) when fossil priors were included, and 102.3 Mya (100.5104.2) using a fixed substitution rate-still a substantial underestimation (Table 2). The genome-wide substitution rate when fossil priors were included was found to be similar $\left(5.88 \times 10^{-9} ; 95 \%\right.$ HPD: $\left.5.78 \times 10^{-9}-5.98 \times 10^{-9}\right)$ to what was documented for $D$. pulex $\left(4.33 \times 10^{-9}\right)$. As before, when we used the two earlier priors on the anomopod root, we observed a consistent pattern in the nuclear substitution rate estimations (i.e. the older the prior, the slower the mutation rate; Early Jurassic: $5.01 \times 10^{-9}, 95 \%$ HPD: $4.92 \times 10^{-9}-5.10 \times 10^{-9}$; Permian: $3.93 \times 10^{-9}, 95 \%$ HPD: 3.86 x $\left.10^{-9}-4.00 \times 10^{-9}\right)$.

\section{Discussion}

High-throughput/next-generation sequencing approaches now enable us to assemble entire genomes and extract genes to explore genome-wide relationships between taxa. In this paper, we have introduced calibrated molecular phylogeny for the family Daphniidae based on entire mitochondrial genomes and 636 nuclear genes. This is the first time a phylogenomic approach has been applied in the Branchiopoda. Although genomic methods have begun to be applied in other microcrustacean groups (i.e. Copepoda, Eyun 2017), major zooplankton groups are still lagging behind in these modern approaches, which are more commonly used for the reconstruction of phylogenies in diverse taxa.

\subsection{Phylogenetic Relationships between non-Daphnia Genera} Whereas the mtDNA and nuclear topologies showed complete agreement about the position of species and species groups within the Daphnia genus, the phylogenetic relationships between non-Daphnia taxa in the family were not as clearly resolved. These differing topologies might, however, reveal important findings for the evolutionary history of the family Daphniidae. The positions of Scapholeberis, as a clade furthest from Daphnia, and of Ceriodaphnia, as (or in) a sister clade to Daphnia, remained consistent in all analyses. The position of both these genera relative to Daphnia was unresolved in previous phylogenies (not focused on Daphniidae) that combined mitochondrial and nuclear genes, where both of these genera showed similar positioning (e.g., deWaard et al., 2006, Richter et al., 2007).

The position of Scapholeberis and its strong divergence in the Daphniidae is 
intriguing and runs counter to classical assumptions about this genus: It is generally assumed that this genus' morphological adaptation to an unusual hyponeustonic

548 lifestyle living below the surface film of the water (such as a specially adapted infolded ventral rim of the valves carapace margin), is an advanced, derived state in the family, forming a synapomorphy with Megafenestra (Dumont and Pensaert, 1983; Fryer, 1991). However, the phylogeny presented here leads us to propose the exact opposite of this "classical" view (see Daphniidae phylogeny in (Dumont and Pensaert, 1983): Fig. XXII). Indeed, we suggest that Scapholeberis may be one of the earliest offshoots in the Daphniidae tree. The morphologically very similar Megafenestra (e.g. Alonso, 1996), which was originally placed within the genus Scapholeberis by taxonomists (and here incorporated for the first time in a wider molecular phylogenetic context), shows unexpectedly large molecular differences from Scapholeberis. This confirms our suggestion that the only two hyponeustonic specialist genera in the Daphniidae likely diverged early in the evolutionary history of the family, to such an extent that they do not cluster together in the nuclear gene tree.

From the nuclear fossil-calibrated phylogeny it seems that the separation of the Scapholeberis lineage happened well before the divergence between the genera Simocephalus or Ceriodaphnia from Daphnia (Fig. S8). The remarkable morphologies of Scapholeberis and Megafenestra, such as the special valve rim and associated rectangular body shape, are considered of secondary origin in the family (Fryer, 1991). The two genera show a different degree of adaptation, with Scapholeberis being the more specialized (Dumont \& Pensaert, 1993). Due to the large genetic distance observed here, we cannot exclude a potential independent evolution of both from a general daphniid stock to the hyponeustonic lifestyle, despite their external similarities.

Because of the discrepancy between the mitochondrial and nuclear gene trees, the exact positions of Simocephalus and Megafenestra remain unclear. In the nuclear tree (Fig. 2; S5), the position of Simocephalus, forming a clade with Megafenestra, even disrupts the classification of the two subfamilies, which would suggest a paraphyly in the Daphniinae as well as in the Scapholeberinae. In the mtDNA tree, however, Simocephalus clusters with Ceriodaphnia, and the subfamilies appear monophyletic. Simocephalus has a lifestyle that differs from closely related taxa: It is neither constantly free-swimming (like Daphnia and Ceriodaphnia), nor hyponeustonic (like Megafenestra and Scapholeberis). Rather, these animals attach themselves dorsally to surfaces most of the time, using the second antennae which included specially adapted setae; Simocephalus behaves more like a sedentary animal exploring different niches from Daphnia (Fryer, 1991; Orlova-Bienkowskaja, 2001).

Finally, because Ceriodaphnia has a consistent phylogenetic position in all analyses (with or without Simocephalus), we hereby consider it the most reliable sister lineage to the genus Daphnia. Both these genera diversified mainly as pelagic free-swimming taxa (Fryer, 1991). The placement of Ceriodaphnia as a direct sister clade to Daphnia has useful implications for ecology and ecotoxicology, as taxa of both genera are widely used as experimental organisms. Future increased taxon 
sampling of non-Daphnia lineages for Daphniidae phylogenomics will help to provide a better understanding of their evolution.

\subsection{The Subgenus Ctenodaphnia}

595

596

597

598

599

600

601

602

603

604

605

606

607

608

609

610

611

612

613

614

615

616

617

618

619

620

621

622

623

624

625

626

627

628

629

630

631

632

633

634
The mtDNA and nuclear topologies showed complete agreement for the position of taxa within the genus Daphnia. Only a portion of the diversity of species and species groups in this diverse genus is represented here, yet some observations can be made. The African endemics D. barbata and D. dolicocephala appear together near the root of the subgenus Ctenodaphnia, followed by a second branch that includes $D$. atkinsoni and the Iberian endemic D. hispanica. Adamowicz et al. (2009) described a similar position for D. barbata, although with low support in their tree; the South African Daphnia dolicocephala has been included here in a larger molecular phylogeny for the first time. This species is part of a group of African endemic daphniids in need of revision (Van Damme et al., 2013). Preliminary data of limb morphologies in Ctenodaphnia suggest that the lineages D. atkinsoni, D. hispanica, D. dolicocephala and D. barbata have some similar features (limbs of "atkinsoni-type"), whereas the limbs of D. magna, D. similis, D. lumholtzi and D. carinata have different sets of morphological characters (Alonso, 1985; Glagolev and Alonso, 1990; and references therein). The present phylogenomic analysis does not contradict such larger divisions in Ctenodaphnia. The close relationship of the Iberian endemic $D$. hispanica to D. atkinsoni also corroborates the thoracic limb characters; indeed, D. hispanica, whose limbs are morphologically closely related to those of $D$. chevreuxi (not included here), harbors several morphological features only found in non-Daphnia genera, which suggests a relatively basal position in the subgenus (Glagolev and Alonso, 1990). The comparison of our phylogenomic analysis with the scarce available data on limb features suggests that limb morphologies may contain a powerful phylogenetic signal for the deeper systematics in Daphnia, as larger clades match general relationships suggested by the preliminary morphological data (e.g. Glagolev and Alonso, 1990).

Our analysis seems to suggest that all Ctenodaphnia clades in basal position are entirely made up of Old World taxa; this is however a result of a sampling bias. Our analysis lacks important lineages such as D. ephemeralis, a critical Nearctic taxon at the basis of the Ctenodaphnia tree in previous phylogenies (Adamowicz et al., 2009); also, the Australian endemic D. pusilla-group was not sampled and only one Australian species from the large $D$. carinata group was included in this study (i.e. $D$. cf. carinata). However, the Old World species, in particular the endemic Ctenodaphnia African species, merit further analysis.

\subsection{The Sister Clade of D. magna is not D. similis}

In the clade leading to D. magna, the Northern Nearctic D. cf. "similis" appears as the closest sister species to $D$. magna among the taxa included here. This taxon is not directly related to other $D$. similis-like species (D. similis, D. sinensis, D. lumholtzi), and is instead likely part of the D. exilis group (Popova et al., 2016). In their study, Popova et al. (2016) cautioned about using D. similis s.str. prematurely as a 
comparative genomic and ecotoxicological model to D. magna. Our phylogenomic analysis supports this caution and shows that better candidates may be found among the D. exilis group, which is restricted to the New World (Adamowicz et al., 2004). We consider this group as a more suitable sister lineage to D. magna for now. The external morphological similarities of $D$. cf. "similis" and $D$. similis seem to be a result of convergence.

The age of divergence in this clade (between D. cf. "similis" and D. magna) is at least 10.6 Mya, according to the conservative estimate using the fossil-calibrated nuclear phylogeny. The split between D. magna and D. cf. "similis" is among the relatively most recent splits in our Ctenodaphnia tree, taking place around the same time as the $D$. similis and $D$. lumholtzi split and more recently than the separation of the latter species from $D$. atkinsoni and $D$. barbata, which happened much earlier, at least 54.4 Mya according to the conservative fossil-calibrated nuclear gene tree. Nuclear data from D. magna suggest that the already reported split between Western Eurasia and Eastern Asia populations (Bekker et al., 2018; Fields et al., 2015; Fields et al., 2018) might have occurred at least 1.2 Mya.

The $D$. similis-group, which is represented in our phylogenomic analysis by two Old World taxa-D. similis s.str. and the recently separated $D$. sinensis-shows that these species delimits are well supported with little intraspecific divergence. They group reliably with $D$. lumholtzi, consistent with previous studies and morphology (Adamowicz et al., 2009; Popova et al., 2016). We reject the suggestion of Popova et al., (2016) that D. barbata is a D. similis-like taxon; in all our analysis, it is far from $D$. similis.

However, our results may be affected by sampling bias. The Australian $D$. carinata-like stock may well contain close sister lineages to $D$. magna, yet they are not studied in more detail here. $D$. cf. carinata is sister-group in our analysis to $D$. similis/D. sinensis/D. lumholtzi, while it appears as a sister lineage to D. exilis in Adamowicz et al., (2009). D. cf. carinata is the sole representative here of a large group of Australian endemics including $D$. jollyi, D. cephalata, D. longicephala and others, several of which are well known for extreme cyclomorphosis (e.g. Hebert, 1978).

\subsection{Gene Tree Discordance}

Because mitochondrial genomes typically do not undergo recombination, mitochondrial genes are often assumed to reconstruct the same topology (Rokas et al., 2003). However, discrepancies between phylogenies based upon different mitochondrial regions may occur due to the way such regions accumulate substitutions (e.g. Meiklejohn et al., 2014; Zhang et al., 2013). Consequently, if researchers have to select one or two mtDNA markers to sequence, their choice of mitochondrial genes greatly influences the reliability of the resulting topology. This discrepancy becomes especially relevant when the aim is to elucidate phylogenetic relationships between species within a old genus, like Daphnia where mtDNA is limited in dealing with deep divergence times due to saturation effects (Rubinoff and Holland, 2005). In most previous phylogenetic studies on Daphnia, the genes COI, $12 \mathrm{~S}$ and $16 \mathrm{~S}$ were selected to represent the mitogenomes as a whole. Our results suggest that $12 \mathrm{~S}$ and $16 \mathrm{~S}$ should indeed be the first choices because they 
showed the lowest K-scores. However, other mitochondrial genes are preferable to COI in phylogenetic studies, as this gene had one of the highest K-scores. Nevertheless, given the abundance of Daphniidae COI sequences in reference see Thielsch et al., 2017)

We observed gene tree discordance among the nuclear genes. Because nuclear genes typically have a limited number of variable characters required to provide a phylogenetically informative signal and build an accurate phylogeny, multigene phylogenies are generally preferred. The markers we used for our phylogenetic analysis were selected from a set of genes known to be highly conserved across a broad range of taxa. Such highly conserved genes are the preferred markers for phylogenetic reconstruction, especially when deep nodes are of interest (e.g. see Nosenko et al., 2013; Zeng et al., 2014; Zhang et al., 2012). Another explanation for nuclear gene discordance is introgression. However, we have no evidence that introgression contributed to nuclear gene tree discordance in our study. Among the species included here, hybridization has been well studied in the D. pulex (Xu et al., 2015) and in the D. longispina complexes (Schwenk and Spaak, 1997). However, sister species of $D$. longispina were not included in our study. Little is known about hybridization in other Daphnia species complexes, although it is known to occur in the D. carinata and D. obtusa complexes as well (Schwenk and Spaak, 1997), though both are represented here by one species, respectively. The approach used in our study of concatenating multiple unlinked genes should reduce, or even overcome, discordant gene topologies, since the discrepancies between single nuclear gene trees and species tree are not expected to occur in the same way for the majority of the genes (Wiens et al., 2010). Incomplete lineage sorting is another alternative explanation for gene tree discordance (Maddison, 1997). Within the genus Daphnia, the species trees obtained using the multi-species coalescent method implemented in ASTRAL were highly supported and identical to the concatenated nuclear ML trees, suggesting that the Daphnia phylogeny observed here is likely not biased by incomplete lineage sorting. The discrepancy in the phylogenetic relationships among non-Daphnia genera between the nucleotide RAxML species trees and the ASTRAL species trees, also highlighted by the consensus tree of DensiTree, suggests that further sampling of non-Daphnia genera may be necessary to provide a better understanding of their relationships.

\subsection{Divergence Time Estimates}

Previous studies have used the molecular clock approach based on a few markers to estimate the divergence time among taxa within the family Daphniidae. However, the age estimate of branching events differs widely in these studies. Our study was not able to fully resolve the known discrepancies regarding the timing of branching events, even though we performed multiple analyses based on different criteria and genetic markers.

Our mtDNA substitution rate-calibrated phylogenies substantially underestimated the time of the Daphnia/Ctenodaphnia split. The same issue was observed for other branching events older than about 20 Mya and is typical of the 
mtDNA "saturation effect," described by DeSalle et al. (1987). The saturation effect can cause homoplasy, making it especially problematic to compare, for example, Drosophila species that diverged $>20$ Mya (Barrio et al., 1992). On the other hand, we observed relatively consistent time estimates for nodes dated $<15$ Mya among mitochondrial and nuclear substitution-rate-based calibration and nuclear-fossilbased calibration. The fact that these multiple independent analyses recover similar time estimates for more recent branching events suggests that the age of such nodes may be useful as minimal estimates. When the mtDNA tree is calibrated with fossil records, the estimates of divergence time are considerably older than when a calibration based on the substitution rate was applied - at least 100 Mya for the divergence between the $D$. longispina and $D$. pulex groups for example, congruent with previous calculations based on mtDNA (16S; Schwenk et al., 2000; Taylor et al., 1996). Although these mtDNA estimates are theoretically possible, however, the discrepancies between the fossil- and substitution rate-calibrated mtDNA phylogenies and the fact that mtDNA describes the history of only one single locus must be taken into account.

Unfortunately, we lack reliable fossils to determine the first appearance of Daphnia species groups, which would strengthen the support for minimal ages of divergence (Van Damme and Kotov, 2016). We know from the fossil record that $D$. "pulex" and D. "magna"-like ephippia (resting eggs) were found in the Eocene palaeolake Messel (ca. 47 Mya; Lutz, 1991) and that well-preserved D. "magnasimilis"-like ephippia and parthenogenetic females were found in Cenozoic German paleolakes (ca. 24 Mya and 17-15 Mya, respectively; Kotov and Wappler, 2015). However, the diagnostic resolution of these ephippia's morphological features does not allow a full identification at the species level. Although the fossil-calibrated nuclear gene time estimates potentially underestimate divergence times (e.g., likely in the timing of the D. magna-D. similis split), the mtDNA estimates may potentially overestimate them (e.g., likely in the separation of D. magna populations between Europe and Asia; Table 2). None of these time-calibrated estimates directly contradicts the fossil record, as there are no reliable records for species groups, yet some estimates may be less plausible. Indeed, any divergence estimates for Daphnia should not be taken as definitive, considering how the results vary depending on the method used. Even fossil calibrations are tentative because of the scarcity of nodes that can be fossil-calibrated. Realistically, only the minimal time estimates based on molecular clocks can be evaluated carefully, and these should always be assessed against an updated fossil record. More paleontological data is necessary to increase the resolution and facilitate the interpretation of such clocks. Even biogeographical data (distribution patterns) is of little help in estimating ages in the genus (Popova and Kotov, 2013).

The nuclear genes proved to be more consistent than the mtDNA when time estimates of fossil- and substitution rate-calibrated phylogenies were compared. Our results contradict what has been suggested by Haag et al. (2009), who dated the split of the subgenera Daphnia/Ctenodaphnia at 7.6 Mya, much more recently than what has been suggested by fossil records (at least $145 \mathrm{Mya}$ ) and the nuclear substitution rate clock shown in our study (at least 100 Mya). This discrepancy may 
be because, in order to calculate divergence times, Haag et al. (2009) used (i) the mutation rates of Drosophila melanogaster and Caenorhabditis elegans, since the mutation rate in Daphnia was not yet known at their time of publication; (ii) only eight nuclear genes and (iii) a mathematical formula that included assumptions about biological parameters such as the effective population size of Daphnia and the number of sexual and asexual generations per year, which are difficult to estimate confidently (Haag et al. (2009) assumed them to be 10). The fact that we obtained relatively similar estimates using two independent approaches-substitution rate (which requires an assumption on the number of generations per year), and fossil data-likely suggests that our choice of using one sexual generation per year (following Lampert, 2011) has some merit.

Using different prior maximum age constraints in a Bayesian analysis can change the time estimates of branching events in a phylogeny (Cracraft et al., 2015; Warnock et al., 2012). Given that no fossils are available to calibrate the MRCA of all Anomopoda accurately, we used three different plausible priors at the root of our tree. When we shifted the prior on the MRCA of all Anomopoda from the Late Jurassic (most recent and most conservative; 145-163.5 Mya) to the Early Jurassic (174-201 Mya) and Permian (252-299 Mya), we found that branching events were estimated to have happened much earlier. It is complicated to speculate on which divergence times are the most realistic because of the lack of fossil evidence older than the Late Jurassic. However, it is likely that the Anomopoda ancestor lived even before the Mesozoic (Van Damme and Kotov, 2016). Nevertheless, when our study estimates the minimum divergence times between taxa using most conservative and reliably dated Late Jurassic prior, we see divergence of most Daphnia species as taking place at least in the Cenozoic (since ca. 66 Mya).

\section{Conclusions}

Our phylogenomic study of the family Daphniidae indicates that topologies obtained from mtDNA and nuclear genomes are similar for younger nodes, but diverge at some of the deep nodes. This is consistent with the suggestion that saturation, causing a loss of signal, occurs in the mtDNA, which represents a single locus (Rubinoff and Holland, 2005). We also observed a major discrepancy in the temporal estimation of branching events for the mtDNA between fossil- and substitution rate-calibrated trees. Our analysis uncovered a new sister taxon to $D$. magna, D. cf. "similis" (D. exilis group) from Western Canada, which can be considered an appropriate outgroup in future phylogenetic and comparative genomic investigations. Also, we established that Ceriodaphnia is the most reliable sister genus to Daphnia, and that the morphologically similar Scapholeberis and Megafenestra show surprisingly deep genetic divergence. We believe that our study provides a solid phylogenetic baseline for future studies involving species of the family Daphniidae and illustrates the power, but also some limitations, of whole genome sequence data for phylogenomic analyses.

\section{Acknowledgements}

We thank Jürgen Hottinger, Urs Stiefel and Michelle Krebs for their help in the lab. 
815 We thank the following people for help in providing samples for this study: Frida 816 Ben-Ami, Maciej Bartosiewicz, Jürgen Hottinger, Lukas Schärer, Yan Galimov, Ian

817 Gardiner, France Dufresne, Jason Andras, Christoph Haag, Tom Little, Joachim 818 Mergeay, Adam Petrusek, Alexey Kotov, Maria José Caramujo R. de Carvalho, Jim 819 Elser, John Havel. We also thank the Editor and two anonymous reviewers whose 820 suggestions helped improve this manuscript. We are grateful to Darren Obbard, 821 Tom Little and Seanna McTaggart (University of Edinburgh), supported by the NERC 822 grant NE/J010790/1, who contributed to the sequencing of some Daphnia clones.

823 We thank the Genomics Facility of Basel (DBSSE), in particular Christian Beisel and

824 Elodie Burcklen, for next generation sequencing service. Part of the analyses for this 825 study was performed using the sciCORE (http://scicore.unibas.ch) scientific 826 computing core facility at the University of Basel. This work was supported by the 827 Swiss National Science Foundation (grant number: 310030B_166677) and the 828 University of Basel. 


\section{References}

831

832

833

834

835

836

837

838

839

840

841

842

843

844

845

846

847

848

849

850

851

852

853

854

855

856

857

858

859

860

861

862

863

864

865

866

867

868

869

870

871

872

873

874

Abascal, F., Zardoya, R., Telford, M.J., 2010. TranslatorX: Multiple alignment of nucleotide sequences guided by amino acid translations. Nucleic Acids Res. 38, 7-13. https://doi.org/10.1093/nar/gkq291

Abele, L.G., Spears, T., 2000. Branchiopod Monophyly and Interordinal Phylogeny Inferred from 18S Ribosomal DNA. J. Crustac. Biol. 20, 1-24. https://doi.org/10.1163/20021975-99990012

Adamowicz, S.J., Hebert, P.D.N., Marinone, M.C., 2004. Species diversity and endemism in the Daphnia of Argentina: a genetic invasion. Zool. J. Linn. Soc. 140, 171-205. https://doi.org/10.1111/j.1096-3642.2003.00089.x

Adamowicz, S.J., Petrusek, A., Colbourne, J.K., Hebert, P.D.N., Witt, J.D.S., 2009. The scale of divergence: A phylogenetic appraisal of intercontinental allopatric speciation in a passively dispersed freshwater zooplankton genus. Mol. Phylogenet. Evol. 50, 423-436. https://doi.org/10.1016/j.ympev.2008.11.026

Alonso, M., 1996. Crustacea, Branchiopoda. En: Fauna Ibérica, vol.7. Ramos, M.A. et al. (Eds.). Museo Nacional de Ciencias Naturales. CSIC. Madrid. 486 pp

Alonso, M., 1985. Daphnia (Ctenodaphnia) Mediterranea: A new species of hyperhaline waters, long confused with $D$. (C.) Dolichocephala Sars, 1895. Hydrobiologia 128, 217-228. https://doi.org/10.1007/BF00006817

Alric, B., Möst, M., Domaizon, I., Pignol, C., Spaak, P., Perga, M.E., 2016. Local human pressures influence gene flow in a hybridizing Daphnia species complex. J. Evol. Biol. 29, 720-735. https://doi.org/10.1111/jeb.12820

Arbogast, B.S., Edwards, S. V., Wakeley, J., Beerli, P., Slowinski, J.B., 2002. Estimating Divergence Times from Molecular Data on Phylogenetic and Population Genetic Timescales. Annu. Rev. Ecol. Syst. 33, 707-740. https://doi.org/10.1146/annurev.ecolsys.33.010802.150500

Barrio, E., Latorre, A., Moya, A., Ayala, F.J., 1992. Phylogenetic reconstruction of the Drosophila obscura group, on the basis of mitochondrial DNA. Mol. Biol. Evol. 9, 621-35.

Barry, M.J., 2000. Inducible defences in Daphnia : responses to two closely related predator species. Oecologia 124, 396-401. https://doi.org/10.1007/s004420000420

Bekker, E.I., Karabanov, D.P., Galimov, Y.R., Haag, C.R., Neretina, T. V, Kotov, A.A., 2018. Phylogeography of Daphnia magna Straus (Crustacea : Cladocera) in Northern Eurasia : Evidence for a deep longitudinal split between mitochondrial lineages. PLoS One 13, e0194045.

Bernt, M., Donath, A., Jühling, F., Externbrink, F., Florentz, C., Fritzsch, G., Pütz, J., Middendorf, M., Stadler, P.F., 2013. MITOS: Improved de novo metazoan mitochondrial genome annotation. Mol. Phylogenet. Evol. 69, 313-319. https://doi.org/10.1016/j.ympev.2012.08.023

Bolger, A.M., Lohse, M., Usadel, B., 2014. Trimmomatic: A flexible trimmer for Illumina sequence data. Bioinformatics 30, 2114-2120. https://doi.org/10.1093/bioinformatics/btu170

Bouckaert, R., Heled, J., Kühnert, D., Vaughan, T., Wu, C.H., Xie, D., Suchard, M.A., Rambaut, A., Drummond, A.J., 2014. BEAST 2: A Software Platform for Bayesian 
875

876

877

878

879

880

881

882

883

884

885

886

887

888

889

890

891

892

893

894

895

896

897

898

899

900

901

902

903

904

905

906

907

908

909

910

911

912

913

914

915

916

917

918

919

Evolutionary Analysis. PLoS Comput. Biol. 10, 1-6. https://doi.org/10.1371/journal.pcbi.1003537

Bouckaert, R.R., 2010. DensiTree: Making sense of sets of phylogenetic trees. Bioinformatics 26, 1372-1373. https://doi.org/10.1093/bioinformatics/btq110

Bromham, L., 2009. Why do species vary in their rate of molecular evolution? Biol. Lett. 5, 401-404. https://doi.org/10.1098/rsbl.2009.0136

Bromham, L., Duchêne, S., Hua, X., Ritchie, A.M., Duchêne, D.A., Ho, S.Y.W., 2018. Bayesian molecular dating: opening up the black box. Biol. Rev. 93, 1165-1191. https://doi.org/10.1111/brv.12390

Castresana, J., 2000. Selection of Conserved Blocks from Multiple Alignments for Their Use in Phylogenetic Analysis. Mol. Biol. Evol. 17, 540-552. https://doi.org/10.1093/oxfordjournals.molbev.a026334

Chevreux, B., Wetter, T., Suhai, S., 1999. Genome Sequence Assembly Using Trace Signals and Additional Sequence Information. Comput. Sci. Biol. Proc. Ger. Conf. Bioinforma. 45-56. https://doi.org/10.1.1.23/7465

Colbourne, J.K., Hebert, P.D.N., 1996. The Systematics of North American Daphnia (Crustacea: Anomopoda): A Molecular Phylogenetic Approach. Philos. Trans. R. Soc. B Biol. Sci. 351, 349-360. https://doi.org/10.1098/rstb.1996.0028

Colbourne, J.K., Pfrender, M.E., Gilbert, D., Thomas, W.K., Tucker, A., Oakley, T.H., Tokishita, S., Aerts, A., Arnold, G.J., Basu, M.K., Bauer, D.J., Caceres, C.E., Carmel, L., Casola, C., Choi, J.-H., Detter, J.C., Dong, Q., Dusheyko, S., Eads, B.D., Froehlich, T., Geiler-Samerotte, K.A., Gerlach, D., Hatcher, P., Jogdeo, S., Krijgsveld, J., Kriventseva, E. V, Kueltz, D., Laforsch, C., Lindquist, E., Lopez, J., Manak, J.R., Muller, J., Pangilinan, J., Patwardhan, R.P., Pitluck, S., Pritham, E.J., Rechtsteiner, A., Rho, M., Rogozin, I.B., Sakarya, O., Salamov, A., Schaack, S., Shapiro, H., Shiga, Y., Skalitzky, C., Smith, Z., Souvorov, A., Sung, W., Tang, Z., Tsuchiya, D., Tu, H., Vos, H., Wang, M., Wolf, Y.I., Yamagata, H., Yamada, T., Ye, Y., Shaw, J.R., Andrews, J., Crease, T.J., Tang, H., Lucas, S.M., Robertson, H.M., Bork, P., Koonin, E. V, Zdobnov, E.M., Grigoriev, I. V, Lynch, M., Boore, J.L., 2011. The Ecoresponsive Genome of Daphnia pulex. Science. 331, 555-561. https://doi.org/10.1126/science.1197761

Cracraft, J., Houde, P., Ho, S.Y.W., Mindell, D.P., Fjeldså, J., Lindow, B., Edwards, S. V., Rahbek, C., Mirarab, S., Warnow, T., Gilbert, M.T.P., Zhang, G., Braun, E.L., Jarvis, E.D., 2015. Response to Comment on "Whole-genome analyses resolve early branches in the tree of life of modern birds." Science. 349, 1460-b. https://doi.org/10.1126/science.aab1578

Crease, T.J., Omilian, A.R., Costanzo, K.S., Taylor, D.J., 2012. Transcontinental Phylogeography of the Daphnia pulex Species Complex. PLoS One 7, e46620. https://doi.org/10.1371/journal.pone.0046620

Darriba, D., Taboada, G.L., Doallo, R., Posada, D., 2012. jModelTest 2: more models, new heuristics and parallel computing. Nat. Methods 9, 772. https://doi.org/10.1038/nmeth.2109

Davidson, R., Vachaspati, P., Mirarab, S., Warnow, T., 2015. Phylogenomic species tree estimation in the presence of incomplete lineage sorting and horizontal 
924

925

926

927

928

929

930

931

932

933

934

935

936

937

938

939

940

941

942

943

944

945

946

947

948

949

950

951

952

953

954

955

956

957

958

959

960

961

962

963

964

gene transfer. BMC Genomics 16, 1-12. https://doi.org/10.1186/1471-216416-S10-S1

DeSalle, R., Freedman, T., Prager, E.M., Wilson, A., 1987. Tempo and mode of sequence evolution in mitochondrial DNA of Hawaiian Drosophila. J. Mol. Evol. $26,157-64$.

deWaard, J.R., Sacherova, V., Cristescu, M.E.A., Remigio, E.A., Crease, T.J., Hebert, P.D.N., 2006. Probing the relationships of the branchiopod crustaceans. Mol. Phylogenet. Evol. 39, 491-502. https://doi.org/10.1016/j.ympev.2005.11.003

Dumont, H.J., Pensaert, J., 1983. A revision of the Scapholeberinae (Crustacea: Cladocera). Hydrobiologia 100, 3-45. https://doi.org/10.1007/BF00027420

Dumont, H.J., Silva-Briano, M., 1998. A reclassification of the anomopod families Macrothricidae and Chydoridae, with the creation of a new suborder, the Radopoda (Crustacea: Branchiopoda). Hydrobiologia 384, 119-149. https://doi.org/10.1023/A:1003259630312

Ebert, D., 2005. Ecology, Epidemiology and Evolution of Parasitism in Daphnia [Internet].Bethesda (MD): National Library of Medicine (US), National Center for BiotechnologyInformation. Available from: http://www.ncbi.nlm.nih.gov/entrez/query.fcgi?db=Books

Edgar, R.C., 2004. MUSCLE: Multiple sequence alignment with high accuracy and high throughput. Nucleic Acids Res. 32, 1792-1797. https://doi.org/10.1093/nar/gkh340

Edwards, S. V., 2009. Natural selection and phylogenetic analysis. Proc. Natl. Acad. Sci. 106, 8799-8800. https://doi.org/10.1073/pnas.0904103106

Engel, K., Tollrian, R., 2009. Inducible defences as key adaptations for the successful invasion of Daphnia lumholtzi in North America? Proc. R. Soc. B Biol. Sci. 276, 1865-1873. https://doi.org/10.1098/rspb.2008.1861

Eyun, S. Il, 2017. Phylogenomic analysis of Copepoda (Arthropoda, Crustacea) reveals unexpected similarities with earlier proposed morphological phylogenies. BMC Evol. Biol. 17, 1-12. https://doi.org/10.1186/s12862-0170883-5

Fields, P.D., Obbard, D.J., Mctaggart, S.J., Galimov, Y., Tom, J., Ebert, D., 2018. Mitogenome phylogeographic analysis of a planktonic crustacean. Mol. Phylogenet. Evol. https://doi.org/10.1016/j.ympev.2018.06.028

Fields, P.D., Reisser, C., Dukic, M., Haag, C.R., Ebert, D., 2015. Genes mirror geography in Daphnia magna. Mol. Ecol. 24, 4521-4536. https://doi.org/10.1111/mec.13324

Fryer, G., 1991. Functional morphology and the adaptive radiation of the Daphniidae (Branchiopoda: Anomopoda). Philos. Trans. R. Soc. London. Ser. B Biol. Sci. 331, 1-99.

Galtier, N., Nabholz, B., Glemin, S., Hurst, G.D.D., 2009. Mitochondrial DNA as a marker of molecular diversity: a reappraisal. Mol. Ecol. 18, 4541-4550. https://doi.org/10.1111/j.1365-294X.2009.04380.x

Glagolev, S.M., Alonso, M., 1990. Daphnia (Ctenodaphnia) hispanica sp. nov., a new daphnid (Cladocera) from Spain. Hydrobiologia 194, 149-162. https://doi.org/10.1007/BF00028416 
965

966

967

968

969

970

971

972

973

974

975

976

977

978

979

980

981

982

983

984

985

986

987

988

989

990

991

992

993

994

995

996

997

998

999

1000

1001

1002

1003

1004

1005

1006

1007

1008

1009
Haag, C.R., McTaggart, S.J., Didier, A., Little, T.J., Charlesworth, D., 2009. Nucleotide polymorphism and within-gene recombination in Daphnia magna and D. pulex, two cyclical parthenogens. Genetics 182, 313-323.

https://doi.org/10.1534/genetics.109.101147

Hahn, C., Bachmann, L., Chevreux, B., 2013. Reconstructing mitochondrial genomes directly from genomic next-generation sequencing reads - A baiting and iterative mapping approach. Nucleic Acids Res. 41, e129. https://doi.org/10.1093/nar/gkt371

Hebert, P.D.N., 1978. The adaptive significance of cyclomorphosis in Daphnia: more possibilities. Freshw. Biol. 8, 313-320. https://doi.org/10.1111/j.13652427.1978.tb01452.x

Herzog, Q., Rabus, M., Ribeiro, B.W., Laforsch, C., 2016. Inducible defenses with a "twist": Daphnia barbata abandons bilateral symmetry in response to an ancient predator. PLoS One 11, e0148556. https://doi.org/10.1371/journal.pone.0148556

Jackman, S.D., Yeo, S., Coombe, L., Warren, R.L., 2017. ABySS 2.0: Resource-Efficient Assembly of Large Genomes using a Bloom Filter. Genome Res. 27, 768-777. https://doi.org/10.1101/gr.214346.116.Freely

Keith, N., Tucker, A.E., Jackson, C.E., Sung, W., Lledó, J.I.L., Schrider, D.R., Schaack, S., Dudycha, J.L., Ackerman, M., Younge, A.J., Shaw, J.R., Lynch, M., 2016. High mutational rates of large-scale duplication and deletion in Daphnia pulex. Genome Res. 26, 60-69. https://doi.org/10.1101/gr.191338.115

Kotov, A., 2013. Morphology and Phylogeny of the Anomopoda (Crustacea: Cladocera). KMW, Moskow.

Kotov, A.A., 2015. A critical review of the current taxonomy of the genus Daphnia 0. F. Müller, 1785 (Anomopoda, Cladocera). Zootaxa 3911, 184-200. https://doi.org/10.11646/zootaxa.3911.2.2

Kotov, A.A., 2007. Jurassic Cladocera (Crustacea, Branchiopoda) with a description of an extinct Mesozoic order. J. Nat. Hist. 41, 13-37. https://doi.org/10.1080/00222930601164445

Kotov, A.A., Taylor, D.J., 2011. Mesozoic fossils ( $>145$ Mya) suggest the antiquity of the subgenera of Daphnia and their coevolution with chaoborid predators. BMC Evol. Biol. 11, 129. https://doi.org/10.1186/1471-2148-11-129

Kotov, A.A., Wappler, T., 2015. Findings of Daphnia (Ctenodaphnia) Dybowski et Grochowski (Branchiopoda: Cladocera) in Cenozoic volcanogenic lakes in Germany, with discussion of their indicator value. Palaeontol. Electron. 1-9. https://doi.org/10.26879/542

Kumar, S., Filipski, A., 2007. Multiple sequence alignment : In pursuit of homologous DNA positions Multiple sequence alignment : In pursuit of homologous DNA positions. Genome Res. 17, 127-135. https://doi.org/10.1101/gr.5232407

Lampert, W., 2011. Daphnia: development of a model organism in ecology and evolution. Excellence in Ecology, Volume 21. International Ecology Institute Publishers, Oldendorf/Luhe, ISSN 0932-2205. 250 pp.

Lutz, H., 1991. Autochthone aquatische Arthropoda aus dem Mittel-Eozän der Fundstätte Messel (Insecta: Heteroptera; Coleoptera; cf. Diptera-Nematocera; 
Crustacea: Cladocera). Cour. Forschungsinstitut Senckenb. 139, 119-125. Maddison, W.P., 1997. Gene trees in species trees. Syst Biol 46, 523-536. https://doi.org/10.1093/sysbio/46.3.523

Marková, S., Dufresne, F., Rees, D.J., Černý, M., Kotlík, P., 2007. Cryptic intercontinental colonization in water fleas Daphnia pulicaria inferred from phylogenetic analysis of mitochondrial DNA variation. Mol. Phylogenet. Evol. 44, 42-52. https://doi.org/10.1016/j.ympev.2006.12.025

Meiklejohn, K.A., Danielson, M.J., Faircloth, B.C., Glenn, T.C., Braun, E.L., Kimball, R.T., 2014. Incongruence among different mitochondrial regions: A case study using complete mitogenomes. Mol. Phylogenet. Evol. 78, 314-323. https://doi.org/10.1016/j.ympev.2014.06.003

Nosenko, T., Schreiber, F., Adamska, M., Adamski, M., Eitel, M., Hammel, J., Maldonado, M., Müller, W.E.G., Nickel, M., Schierwater, B., Vacelet, J., Wiens, M., Wörheide, G., 2013. Deep metazoan phylogeny: When different genes tell different stories. Mol. Phylogenet. Evol. 67, 223-233. https://doi.org/10.1016/j.ympev.2013.01.010

Orlova-Bienkowskaja, M.Y., 2001. Cladocera: Anomopoda: Daphniidae, genus Simocephalus. Guides to the identification of the microinvertebrates of the continental waters of the World. Vol. 17. Backhuys, Leyden, $130 \mathrm{pp}$.

Orsini, L., Mergeay, J., Vanoverbeke, J., De Meester, L., 2013. The role of selection in driving landscape genomic structure of the waterflea Daphnia magna. Mol. Ecol. 22, 583-601. https://doi.org/10.1111/mec.12117

Paradis, E., Claude, J., Strimmer, K., 2004. APE: Analyses of phylogenetics and evolution in R language. Bioinformatics 20, 289-290. https://doi.org/10.1093/bioinformatics/btg412

Petrusek, A., Hobæk, A., Nilssen, J.P., Skage, M., Černý, M., Brede, N., Schwenk, K., 2008. A taxonomic reappraisal of the European Daphnia longispina complex (Crustacea, Cladocera, Anomopoda). Zool. Scr. 37, 507-519. https://doi.org/10.1111/j.1463-6409.2008.00336.x

Petrusek, A., Tollrian, R., Schwenk, K., Haas, A., Laforsch, C., 2009. A "crown of thorns" is an inducible defense that protects Daphnia against an ancient predator. Proc. Natl. Acad. Sci. 106, 2248-2252. https://doi.org/10.1073/pnas.0808075106

Popova, E.Y., Kotov, A.A., 2013. Latitudinal patterns in the diversity of two subgenera of the genus Daphnia O.F. Müller (Crustacea: Cladocera: Daphniidae). Zootaxa 3736, 159-174. https://doi.org/10.11646/zootaxa.3736.2.4

Popova, E. V., Petrusek, A., Kořínek, V., Mergeay, J., Bekker, E.I., Karabanov, D.P., Galimov, Y.R., Neretina, T. V., Taylor, D.J., Kotov, A.A., 2016. Revision of the old world Daphnia (Ctenodaphnia) similis group (Cladocera: Daphniidae). Zootaxa 4161, 1-40. https://doi.org/10.11646/zootaxa.4161.1.1

Rambaut, A., Suchard, M.A., Xie, D., Drummond, A.J., 2014. Tracer v1.6. Available from: http://tree.bio.ed.ac.uk/software/tracer/.

Raymond, P.E., 1946. The genera of fossil Conchostracan order of bivalved Crustacea. Bull. Museum Comp. Zool. 96, 215-307.

Richter, S., Olesen, J., Wheeler, W.C., 2007. Phylogeny of Branchiopoda (Crustacea) based on a combined analysis of morphological data and six molecular loci. 
1055

1056

1057

1058

1059

1060

1061

1062

1063

1064

1065

1066

1067

1068

1069

1070

1071

1072

1073

1074

1075

1076

1077

1078

1079

1080

1081

1082

1083

1084

1085

1086

1087

1088

1089

1090

1091

1092

1093

1094

1095

1096

1097

1098

1099

Cladistics 23, 301-336.

Rieux, A., Balloux, F., 2016. Inferences from tip-calibrated phylogenies: A review and a practical guide. Mol. Ecol. 25, 1911-1924. https://doi.org/10.1111/mec.13586

Rodgher, S., Espíndola, E.L.G., Lombardi, A.T., 2010. Suitability of Daphnia similis as an alternative organism in ecotoxicological tests: Implications for metal toxicity. Ecotoxicology 19, 1027-1033. https://doi.org/10.1007/s10646-010-0484-1

Rokas, A., Ladoukakis, E., Zouros, E., 2003. Animal mitochondrial DNA recombination revisited. Trends Ecol. Evol. 18, 411-417. https://doi.org/10.1016/S0169-5347(03)00125-3

Rota-Stabelli, O., Telford, M.J., 2008. A multi criterion approach for the selection of optimal outgroups in phylogeny: Recovering some support for Mandibulata over Myriochelata using mitogenomics. Mol. Phylogenet. Evol. 48, 103-111. https://doi.org/10.1016/j.ympev.2008.03.033

Rubinoff, D., Holland, B.S., 2005. Between Two Extremes: Mitochondrial DNA is neither the Panacea nor the Nemesis of Phylogenetic and Taxonomic Inference. Syst. Biol. 54, 952-961. https://doi.org/10.1080/10635150500234674

Salichos, L., Rokas, A., 2013. Inferring ancient divergences requires genes with strong phylogenetic signals. Nature 497, 327-331. https://doi.org/10.1038/nature12130

Schwenk, K., Posada, D., Hebert, P.D.N., 2000. Molecular systematics of European Hyalodaphnia: the role of contemporary hybridization in ancient species. Proc. R. Soc. B Biol. Sci. 267, 1833-1842. https://doi.org/10.1098/rspb.2000.1218 Schwenk, K., Spaak, P., 1997. Ecology and genetics of interspecific hybridization in Daphnia, In B. Streit, T. Staedler, \& C. M. Lively (Eds.), Ecology and Evolution of Freshwater Animals (pp. 199-229). Basel: Birkhäuser Verlag.

Shaw, J.R., Pfrender, M.E., Eads, B.D., Klaper, R., Callaghan, A., Sibly, R.M., Colson, I., Jansen, B., Gilbert, D., Colbourne, J.K., 2008. Daphnia as an emerging model for toxicological genomics. Adv. Exp. Biol. 2, 5-7. https://doi.org/10.1016/S18722423(08)00005-7

Simmons, M.P., 2017. Relative benefits of amino-acid, codon, degeneracy, DNA, and purine-pyrimidine character coding for phylogenetic analyses of exons. J. Syst. Evol. 55, 85-109. https://doi.org/10.1111/jse.12233

Simmons, M.P., Carr, T.G., O'Neill, K., 2004. Relative character-state space, amount of potential phylogenetic information, and heterogeneity of nucleotide and amino acid characters. Mol. Phylogenet. Evol. 32, 913-926. https://doi.org/10.1016/j.ympev.2004.04.011

Simmons, M.P., Ochoterena, H., Freudenstein, J. V., 2002. Amino acid vs. nucleotide characters: Challenging preconceived notions. Mol. Phylogenet. Evol. 24, 78-90. https://doi.org/10.1016/S1055-7903(02)00202-6

Soria-Carrasco, V., Talavera, G., Igea, J., Castresana, J., 2007. The K tree score: Quantification of differences in the relative branch length and topology of phylogenetic trees. Bioinformatics 23, 2954-2956. https://doi.org/10.1093/bioinformatics/btm466

Stamatakis, A., 2014. RAxML version 8: a tool for phylogenetic analysis and post- 
1100

1101

1102

1103

1104

1105

1106

1107

1108

1109

1110

1111

1112

1113

1114

1115

1116

1117

1118

1119

1120

1121

1122

1123

1124

1125

1126

1127

1128

1129

1130

1131

1132

1133

1134

1135

1136

1137

1138

1139

1140

1141

1142

1143

1144

analysis of large phylogenies. Bioinformatics 30, 1312-3.

https://doi.org/10.1093/bioinformatics/btu033

Stenderup, J.T., Olesen, J., Glenner, H., 2006. Molecular phylogeny of the Branchiopoda (Crustacea)-Multiple approaches suggest a "diplostracan" ancestry of the Notostraca. Mol. Phylogenet. Evol. 41, 182-194. https://doi.org/10.1016/j.ympev.2006.06.006

Stollewerk, A., 2010. The water flea Daphnia--a "new" model system for ecology and evolution? J. Biol. 9, 21. https://doi.org/10.1186/jbiol212

Sun, X.Y., Xia, X., Yang, Q., 2016. Dating the origin of the major lineages of Branchiopoda. Palaeoworld 25, 303-317. https://doi.org/10.1016/j.palwor.2015.02.003

Swain, T.D., Taylor, D.J., 2003. Structural rRNA characters support monophyly of raptorial limbs and paraphyly of limb specialization in water fleas. Proc. R. Soc. B Biol. Sci. 270, 887-896. https://doi.org/10.1098/rspb.2002.2297

Taylor, D.J., Hebert, P.D.N., Colbourne, J.K., 1996. Phylogenetics and evolution of the Daphnia longispina group (Crustaceae) based on 12S r DNA sequence and allozyme variation. Mol. Phylogenet. Evol. 5, 495-510.

Thielsch, A., Knell, A., Mohammadyari, A., Petrusek, A., Schwenk, K., 2017. Divergent clades or cryptic species? Mito-nuclear discordance in a Daphnia species complex. BMC Evol. Biol. 17, 1-9. https://doi.org/10.1186/s12862-017-1070-4

Tucker, A.E., Ackerman, M.S., Eads, B.D., Xu, S., Lynch, M., 2013. Population-genomic insights into the evolutionary origin and fate of obligately asexual Daphnia pulex. Proc. Natl. Acad. Sci. U. S. A. 110, 15740-5. https://doi.org/10.1073/pnas.1313388110

Vaidya, G., Lohman, D.J., Meier, R., 2011. SequenceMatrix: Concatenation software for the fast assembly of multi-gene datasets with character set and codon information. Cladistics 27, 171-180. https://doi.org/10.1111/j.10960031.2010.00329.x

Van Damme, K., Bekker, E.I., Kotov, A.A., 2013. Endemism in the Cladocera (Crustacea: Branchiopoda) of Southern Africa. J. Limnol. 72, 440-463. https://doi.org/10.4081/jlimnol.2013.e36

Van Damme, K., Kotov, A.A., 2016. The fossil record of the Cladocera (Crustacea: Branchiopoda): Evidence and hypotheses. Earth-Science Rev. 163, 162-189. https://doi.org/10.1016/j.earscirev.2016.10.009

Van Damme, K., Shiel, R.J., Dumont, H.J., 2007. Notothrix halsei gen. n., sp. n., representative of a new family of freshwater cladocerans (Branchiopoda, Anomopoda) from SW Australia, with a discussion of ancestral traits and a preliminary molecular phylogeny of the order. Zool. Scr. 36, 465-487. https://doi.org/10.1111/j.1463-6409.2007.00292.x

Warnock, R.C.M., Yang, Z., Donoghue, P.C.J., 2012. Exploring uncertainty in the calibration of the molecular clock. Biol. Lett. 8, 156-159. https://doi.org/10.1098/rsbl.2011.0710

Waterhouse, R.M., Seppey, M., Simão, F.A., Manni, M., Ioannidis, P., Klioutchnikov, G., Kriventseva, E. V, Zdobnov, E.M., 2017. BUSCO Applications from Quality Assessments to Gene Prediction and Phylogenomics. Mol. Biol. Evol. 1-6. 
1145

1146

1147

1148

1149

1150

1151

1152

1153

1154

1155

1156

1157

1158

1159

1160

1161

1162

1163

1164

1165

1166

1167

1168

1169

1170

1171

1172

1173

1174

1175

1176

1177

1178

1179

1180

1181

1182 https://doi.org/10.1093/molbev/msx319

Wiens, J.J., Kuczynski, C.A., Stephens, P.R., 2010. Discordant mitochondrial and nuclear gene phylogenies in emydid turtles: Implications for speciation and conservation. Biol. J. Linn. Soc. 99, 445-461. https://doi.org/10.1111/j.10958312.2009.01342.x

Xu, S., Schaack, S., Seyfert, A., Choi, E., Lynch, M., Cristescu, M.E., 2012. High mutation rates in the mitochondrial genomes of Daphnia pulex. Mol. Biol. Evol. 29, 763769. https://doi.org/10.1093/molbev/msr243

Xu, S., Spitze, K., Ackerman, M.S., Ye, Z., Bright, L., Keith, N., Jackson, C.E., Shaw, J.R., Lynch, M., 2015. Hybridization and the origin of contagious asexuality in Daphnia pulex. Mol. Biol. Evol. 32, 3215-3225. https://doi.org/10.1093/molbev/msv190

Ye, Z., Xu, S., Spitze, K., Asselman, J., Jiang, X., Ackerman, M.S., Lopez, J., Harker, B., Raborn, R.T., Thomas, W.K., Ramsdell, J., Pfrender, M.E., Lynch, M., 2017. A New Reference Genome Assembly for the Microcrustacean Daphnia pulex 7, 14051416. https://doi.org/10.1534/g3.116.038638/-/DC1.1

Zeng, L., Zhang, Q., Sun, R., Kong, H., Zhang, N., Ma, H., 2014. Resolution of deep angiosperm phylogeny using conserved nuclear genes and estimates of early divergence times. Nat. Commun. 5, 1-12. https://doi.org/10.1038/ncomms5956

Zhang, C., Rabiee, M., Sayyari, E., Mirarab, S., 2018. ASTRAL-III: Polynomial time species tree reconstruction from partially resolved gene trees. BMC Bioinformatics 19, 15-30. https://doi.org/10.1186/s12859-018-2129-y

Zhang, N., Zeng, L., Shan, H., Ma, H., 2012. Highly conserved low-copy nuclear genes as effective markers for phylogenetic analyses in angiosperms. New Phytol. 195, 923-937. https://doi.org/10.1111/j.1469-8137.2012.04212.x

Zhang, P., Liang, D., Mao, R.L., Hillis, D.M., Wake, D.B., Cannatella, D.C., 2013. Efficient sequencing of anuran mtDNAs and a mitogenomic exploration of the phylogeny and evolution of frogs. Mol. Biol. Evol. 30, 1899-1915. https://doi.org/10.1093/molbev/mst091

Zhu, T., Reis, M. Dos, Yang, Z., 2015. Characterization of the uncertainty of divergence time estimation under relaxed molecular clock models using multiple loci. Syst. Biol. 64, 267-280. https://doi.org/10.1093/sysbio/syu109

Zimin, A. V., Marçais, G., Puiu, D., Roberts, M., Salzberg, S.L., Yorke, J.A., 2013. The MaSuRCA genome assembler. Bioinformatics 29, 2669-2677. https://doi.org/10.1093/bioinformatics/btt476 


\section{Figure Captions}

1184

1185 Figure 1. MtDNA Maximum Likelihood tree. This tree is based on the 13 PCGs and 1186 rRNA genes. Bootstrap values are reported beside internal nodes.

1187

1188

Figure 2. Genome-wide nuclear Maximum Likelihood phylogeny. This tree is based 1189 on 636 nuclear genes. Bootstrap values from the RAxML analysis are reported above 1190 the nodes and local posterior probability values from the ASTRAL analysis are 1191 reported below the nodes.

1192

1193 Figure 3. DensiTree of the nuclear genes. In this figure only one representative per 1194 species was included in order to facilitate the visualization. D. cf. carinata is not 1195 included here due to its relevant number of missing genes. The topology of each 1196 nuclear tree is drawn in green and the blue consensus tree has been obtained using 1197 the 'root canal' function of DensiTree.

1198

1199 


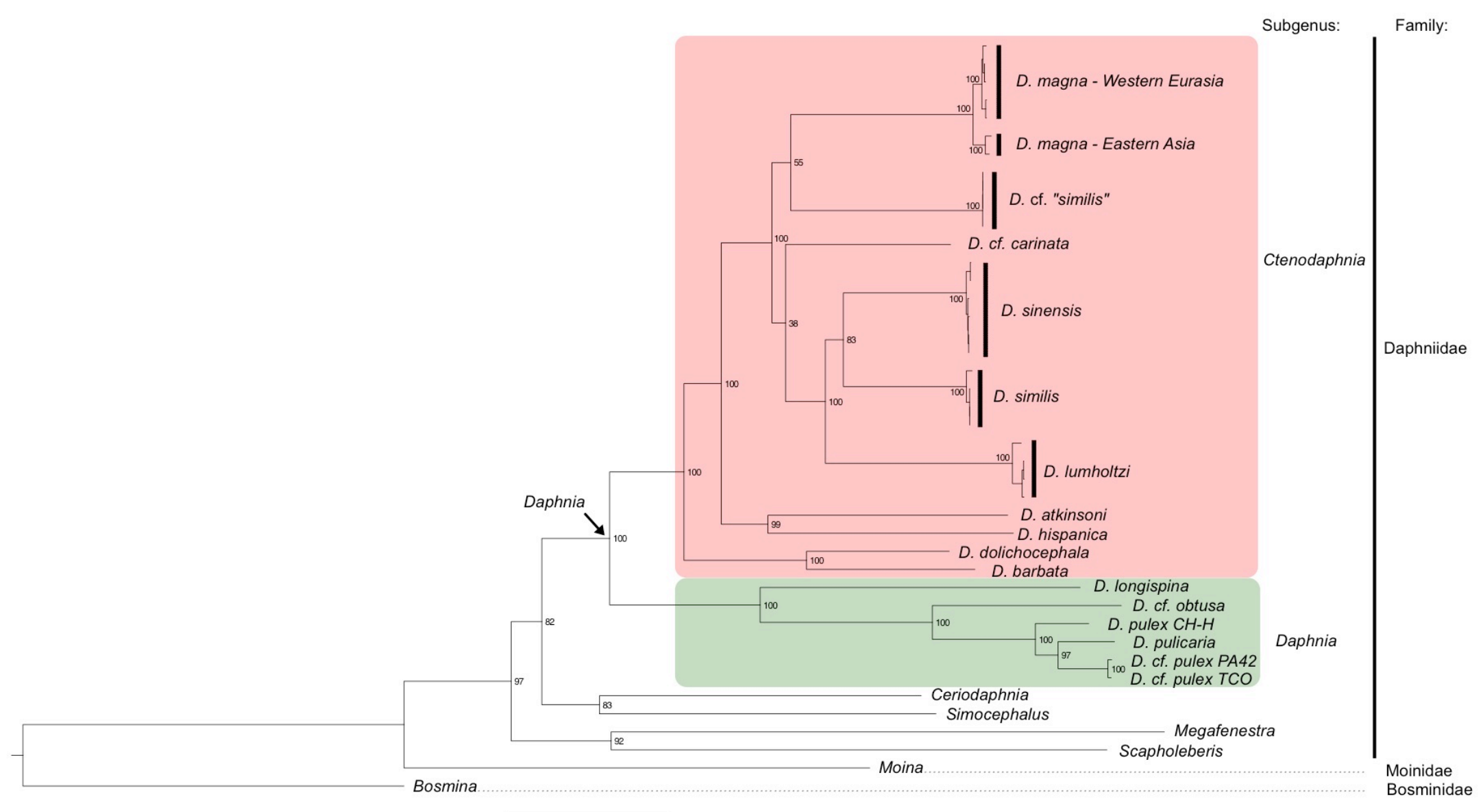




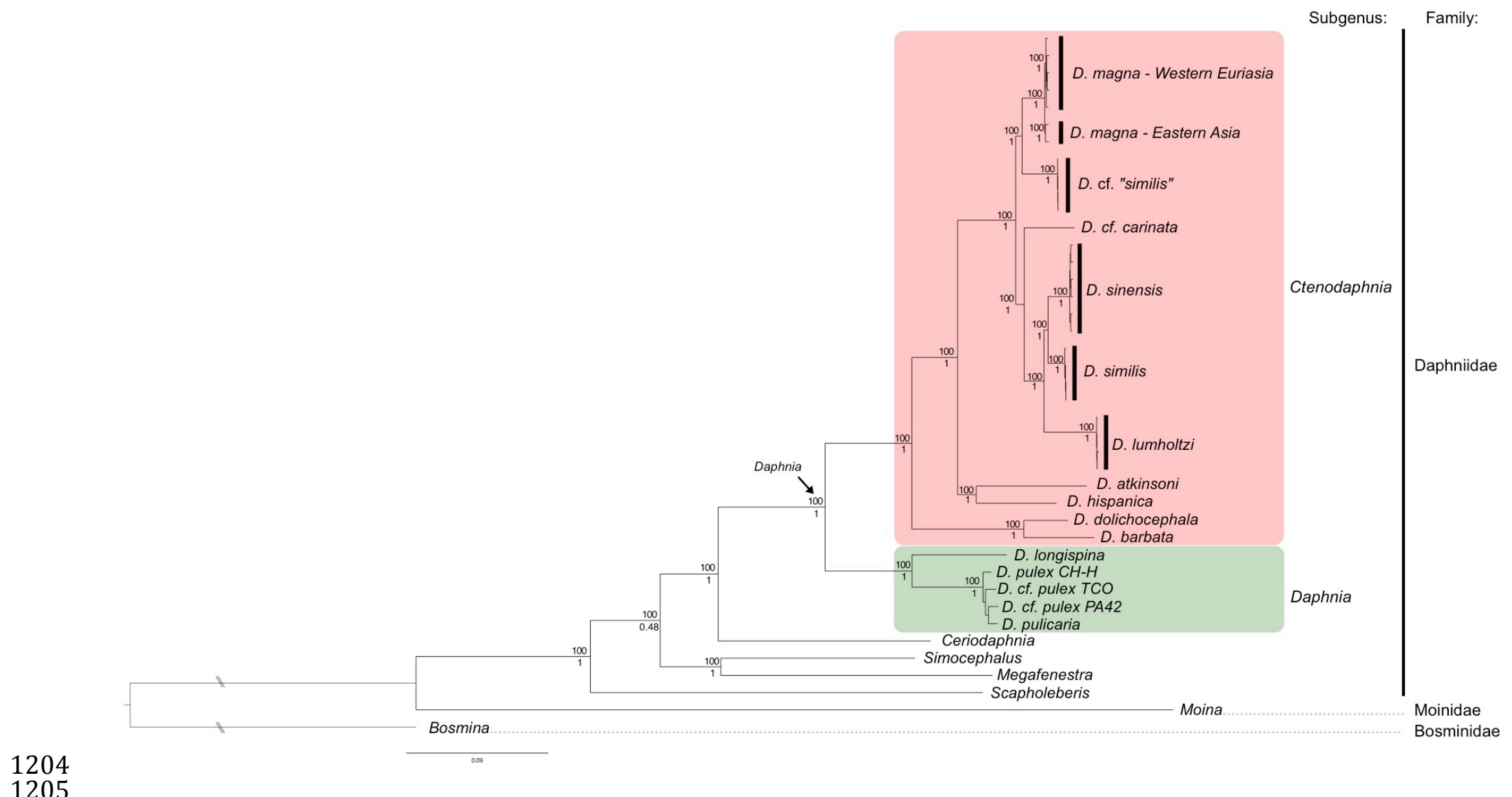




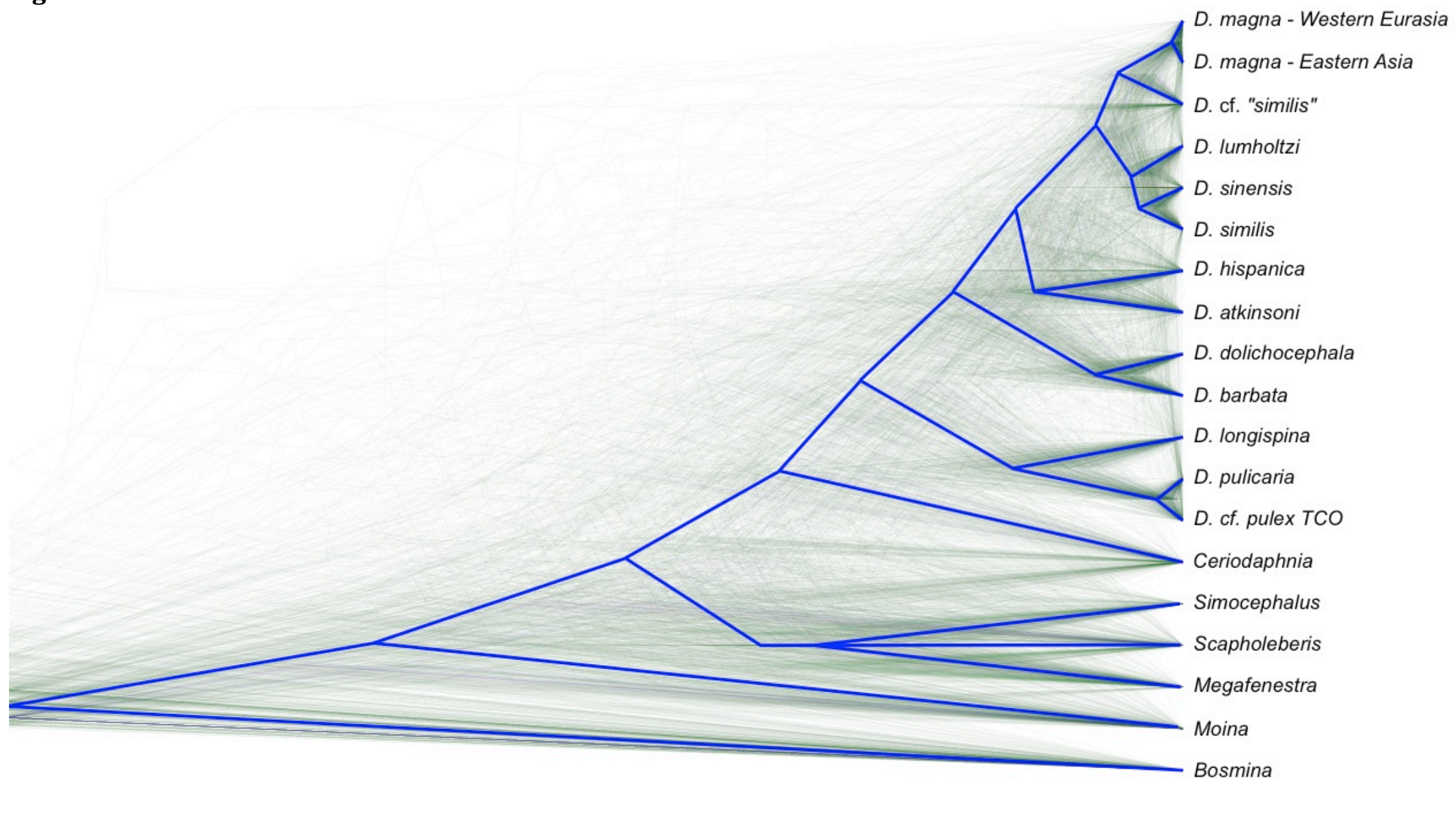


1209 Table 1. List and details of cladoceran clones included in this study

1210

1211

\begin{tabular}{|c|c|c|c|c|c|c|c|}
\hline Family & Genus & Subgenus & Species (Species group) & Country & Clone name & Latitude & Longitude \\
\hline Bosminidae & Bosmina & Eubosmina & $\begin{array}{l}\text { Bosmina cf. longispina maritima ( } B . \\
\text { coregoni group) }\end{array}$ & Finland & $\begin{array}{l}\text { Bosmina_cf.longispina_mar } \\
\text { itima_FI-BAL1-1 }\end{array}$ & 59.845123 & 23.249092 \\
\hline Moinidae & Moina & & Moina brachiata (M. brachiata group) & Germany & Moina_sp_DE-FRO-2-1 & 48.214947 & 11.613311 \\
\hline Daphniidae & Megafenestra & & Megafenestra aurita & Switzerland & $\begin{array}{l}\text { Megafenestra_aurita_CH-H- } \\
2\end{array}$ & 47.557769 & 8.862608 \\
\hline Daphniidae & Scapholeberis & & $\begin{array}{l}\text { Scapholeberis mucronata (S. mucronata } \\
\text { group) }\end{array}$ & Belgium & $\begin{array}{l}\text { Scapholeberis_mucronata } \\
\text { BE-ASS }\end{array}$ & 51.04907 & 3.666028 \\
\hline Daphniidae & Simocephalus & & $\begin{array}{l}\text { Simocephalus cf. serrulatus (S. serrulatus } \\
\text { group) }\end{array}$ & Oman & $\begin{array}{l}\text { Simocephalus_cf_serrulatus } \\
\text { _OM-SAIQ-clone2 }\end{array}$ & 23.079561 & 57.670617 \\
\hline Daphniidae & Ceriodaphnia & & $\begin{array}{l}\text { Ceriodaphnia cf. reticulata (C. reticulata } \\
\text { group) }\end{array}$ & Oman & $\begin{array}{l}\text { Ceriodaphnia_sp_OM-SAIQ- } \\
\text { clone2 }\end{array}$ & 23.079561 & 57.670617 \\
\hline Daphniidae & Daphnia & Ctenodaphnia & D. cf. carinata (D. carinata group) & Australia & $\begin{array}{l}\text { D.cf."carinata"_group_AU- } \\
\text { BEG-1 }\end{array}$ & -38.268732 & 144.536689 \\
\hline Daphniidae & Daphnia & Ctenodaphnia & D. cf. "similis" (D. exilis group) & Canada & D.cf."similis"_CA-CBC-31 & 49.567824 & -115.725945 \\
\hline Daphniidae & Daphnia & Ctenodaphnia & D. cf. "similis" (D. exilis group) & Canada & D.cf."similis"_CA-CBC-34 & 49.567824 & -115.725945 \\
\hline Daphniidae & Daphnia & Ctenodaphnia & D. cf. "similis" (D. exilis group) & Canada & D.cf."similis"_CA-CBC-37 & 49.567824 & -115.725945 \\
\hline Daphniidae & Daphnia & Ctenodaphnia & D. cf. "similis" (D. exilis group) & Canada & D.cf."similis"_CA-CBC-38 & 49.567824 & -115.725945 \\
\hline Daphniidae & Daphnia & Ctenodaphnia & D. atkinsoni (D. atkinsoni group) & Israel & D.atkinsoni_IL-KID-3b-11 & 31.267059 & 35.233988 \\
\hline Daphniidae & Daphnia & Ctenodaphnia & D. barbata & Zimbabwe & D.barbata_ZW-BAR-1 & -17.897591 & 30.791585 \\
\hline Daphniidae & Daphnia & Ctenodaphnia & D. dolichocephala & South Africa & D.dolichocephala_ZA-DOLI & NA & NA \\
\hline Daphniidae & Daphnia & Ctenodaphnia & D. hispanica & Portugal & D.hispanica_PT-GA-1 & 37.05066400 & -7.97930600 \\
\hline Daphniidae & Daphnia & Ctenodaphnia & D. lumholtzi (D. similis group) & India & D.lumholtzi_IN-PA-1 & 18.5204 & 73.8567 \\
\hline Daphniidae & Daphnia & Ctenodaphnia & D. lumholtzi (D. similis group) & USA & D.lumholtzi_US-AR & 33.543495 & -111.435493 \\
\hline Daphniidae & Daphnia & Ctenodaphnia & D. lumholtzi (D. similis group) & USA & D.lumholtzi_US-MO & 37.597924 & -93.711006 \\
\hline Daphniidae & Daphnia & Ctenodaphnia & D. lumholtzi (D. similis group) & Zimbabwe & D.lumholtzi_ZW-LUM & NA & NA \\
\hline Daphniidae & Daphnia & Ctenodaphnia & D. magna & USA & CA-CH-1 & 58.770982 & -93.850837 \\
\hline Daphniidae & Daphnia & Ctenodaphnia & D. magna & Switzerland & CH-H-1 & 47.557769 & 8.862608 \\
\hline Daphniidae & Daphnia & Ctenodaphnia & D. magna & Finland & FI-XINB3 & 59.833183 & 23.260387 \\
\hline
\end{tabular}




\begin{tabular}{|c|c|c|c|c|c|c|c|}
\hline Daphniidae & Daphnia & Ctenodaphnia & D. magna & France & FR-SA-1 & 43.48012 & 4.647302 \\
\hline Daphniidae & Daphnia & Ctenodaphnia & D. magna & UK & GB-EK1-32 & 55.702406 & -2.340828 \\
\hline Daphniidae & Daphnia & Ctenodaphnia & D. magna & Mongolia & MN-DM1-1 & 45.032708 & 100.660481 \\
\hline Daphniidae & Daphnia & Ctenodaphnia & D. magna & Central Asia & RU-SAM5 & 52.92296 & 50.31727 \\
\hline Daphniidae & Daphnia & Ctenodaphnia & D. similis (D. similis group) & Israel & D.similis_IL-B-3 & 32.01325 & 34.963211 \\
\hline Daphniidae & Daphnia & Ctenodaphnia & D. similis (D. similis group) & Israel & D.similis_IL-KYN-4 & 32.130706 & 34.811168 \\
\hline Daphniidae & Daphnia & Ctenodaphnia & D. similis (D. similis group) & Israel & D.similis_IL-NS-13 & 31.724185 & 34.626269 \\
\hline Daphniidae & Daphnia & Ctenodaphnia & D. similis (D. similis group) & Israel & $\begin{array}{l}\text { D.similis_IL-SIM-A20-inb3- } \\
14\end{array}$ & 32.781095 & 35.407369 \\
\hline Daphniidae & Daphnia & Ctenodaphnia & D. sinensis (D. similis group) & Russia & D.sinensis_RU-BU1-3 & 51.231333 & 108.3035 \\
\hline Daphniidae & Daphnia & Ctenodaphnia & D. sinensis (D. similis group) & Russia & D.sinensis_RU-NOV1-01 & 55.127795 & 77.037327 \\
\hline Daphniidae & Daphnia & Ctenodaphnia & D. sinensis (D. similis group) & Russia & D.sinensis_RU-SZB3 & 50.347667 & 114.873833 \\
\hline Daphniidae & Daphnia & Ctenodaphnia & D. sinensis (D. similis group) & Russia & D.sinensis_RU-TU2-01 & 55.713667 & 68.991 \\
\hline Daphniidae & Daphnia & Ctenodaphnia & D. sinensis (D. similis group) & Russia & D.sinensis_RU-TY6-1 & 50.2555 & 89.546833 \\
\hline Daphniidae & Daphnia & Ctenodaphnia & D. sinensis (D. similis group) & Russia & D.sinensis_RU-TY6-3 & 50.2555 & 89.546833 \\
\hline Daphniidae & Daphnia & Daphnia & D. cf. obutsa (D. obtusa group) & USA & D.cf.obtusa & NA & NA \\
\hline Daphniidae & Daphnia & Daphnia & D. pulex (D. pulex group) & Switzerland & D.pulex_CH-H & 47.557769 & 8.862608 \\
\hline Daphniidae & Daphnia & Daphnia & D. cf. pulex (D. pulex group) & USA & D.cf.pulex_PA42 & 40.2013 & -87.3294 \\
\hline Daphniidae & Daphnia & Daphnia & D. cf. pulex (D. pulex group) & USA & D.cf.pulex_TCO & 43.830013 & -124.148152 \\
\hline Daphniidae & Daphnia & Daphnia & D. pulicaria (D. pulex group) & Czech Republic & D.pulicaria_CZ-RIM1-1 & 48.845027 & 14.484201 \\
\hline Daphniidae & Daphnia & Daphnia & D. longispina (D. longispina group) & Finland & $\begin{array}{l}\text { D.longispina_FI-G-95- } \\
\text { 1_INB4-1 }\end{array}$ & 59.814996 & 23.248143 \\
\hline
\end{tabular}

1212

1213 
1214

Table 2. Divergence times obtained using calibration based on fossil records and substitution rate for mtDNA (all 13 PCGs and rRNA genes) and nuclear genes (four-fold degenerate sites). The median and the $95 \% \mathrm{CI}$ are reported. We also reported the different estimates obtained with different priors applied to the most recent common ancestor of all Anomopoda (i.e. Late Jurassic, Early Jurassic and Permian). Four additional priors are used in the fossil calibration analysis (see main text for details).

node age (Mya [95\% HPD])

\begin{tabular}{|c|c|c|c|c|c|c|}
\hline dataset & $\begin{array}{l}\text { subgenus Daphnia- } \\
\text { Ctenodaphnia }\end{array}$ & $\begin{array}{l}\text { D. longispina - } \\
\text { D. pulex group }\end{array}$ & $\begin{array}{l}\text { D. magna - } \\
\text { D. sinensis }\end{array}$ & $\begin{array}{l}\text { D. magna - } \\
\text { D. cf. "similis" }\end{array}$ & $\begin{array}{l}\text { D. similis - } \\
\text { D. sinensis }\end{array}$ & $\begin{array}{l}\text { D. magna (Europe) - } \\
\text { D. magna (Asia) }\end{array}$ \\
\hline $\begin{array}{l}\text { mtDNA - fossil calibration - Late } \\
\text { Jurassic }\end{array}$ & $145.2[145.0-145.5]$ & 104.7 [101.1-108.3] & $74.1[71.9-76.5]$ & $66.6[63.8-69.6]$ & $47.8[45.6-50.1]$ & $6.9[6.4-7.4]$ \\
\hline $\begin{array}{l}\text { mtDNA - fossil calibration - Early } \\
\text { Jurassic }\end{array}$ & $146.1[145.1-147.6]$ & 110.6 [106.9-114.2] & $81.1[78.6-83.7]$ & $73.0[69.9-76.2]$ & $52.5[49.9-55.0]$ & $7.6[7.0-8.2]$ \\
\hline $\begin{array}{l}\text { mtDNA - fossil calibration - } \\
\text { Permian }\end{array}$ & $175.4[167.0-187.1]$ & $133.9[126.2-143.1]$ & 99.0 [93.4-105.3] & $89.4[84.1-95.8]$ & $64.1[59.9-68.9]$ & $9.3[8.5-10.2]$ \\
\hline mtDNA - substitution rate & 26.9 [26.1-27.8] & $20.3[19.5-21.2]$ & $14.9[14.4-15.4]$ & $13.5[12.8-14.1]$ & $9.7[9.2-10.1]$ & $1.4[1.3-1.5]$ \\
\hline $\begin{array}{l}\text { nuclear genes - fossil calibration - } \\
\text { Late Jurassic }\end{array}$ & $145.0[145.0-145.1]$ & $31.5[30.6-32.3]$ & $16.3[15.9-16.6]$ & $10.9[10.6-11.3]$ & $7.6[7.3-7.8]$ & $1.3[1.2-1.4]$ \\
\hline $\begin{array}{l}\text { nuclear genes - fossil calibration - } \\
\text { Early Jurassic }\end{array}$ & $145.0[145.0-145.1]$ & $37.0[36.1-37.9]$ & $19.0[18.6-19.4]$ & $12.8[12.4-13.2]$ & $8.8[8.5-9.1]$ & $1.5[1.4-1.6]$ \\
\hline $\begin{array}{l}\text { nuclear genes - fossil calibration - } \\
\text { Permian }\end{array}$ & $145.1[145.0-145.2]$ & $47.3[46.1-48.5]$ & $24.2[23.7-24.8]$ & $16.3[15.8-16.8]$ & $11.3[10.9-11.6]$ & $1.9[1.8-2.0]$ \\
\hline nuclear genes - substitution rate & $102.2[100.4-104.8]$ & $41.7[40.7-42.8]$ & $21.9[21.5-22.4]$ & $14.5[14.1-14.9]$ & $10.4[10.1-10.9]$ & $1.7[1.6-1.8]$ \\
\hline
\end{tabular}




\section{A Fossil-Calibrated Phylogenomic Analysis of Daphnia and the Daphniidae}

Luca Cornetti $^{1}$, Peter D. Fields ${ }^{1}$, Kay Van Damme ${ }^{2,3}$ and Dieter Ebert ${ }^{1}$

1 University of Basel, Department of Environmental Sciences, Zoology, Vesalgasse 1, 4051 Basel, Switzerland

2 Senckenberg Research Institute and Natural History Museum Frankfurt, Senckenberganlage 25, 60325 Frankfurt am Main, Germany

${ }^{3}$ Tvärminne Zoological Station, University of Helsinki, J.A. Palménin tie 260, Hanko, Finland

Corresponding author: L. Cornetti, E-mail: luca.cornetti@unibas.ch 
Figure S1. ML tree including our newly obtained sequences (highlighted in green and named according to column "Clone name" in Table al., (2009) that were sequenced for 12S, 16S and COI. For the latter taxa, the same labels as in Adamowicz et al., (2009) were used. Where 1242 applicable, we provided additional labeling for species, species groups, genera and subgenera.

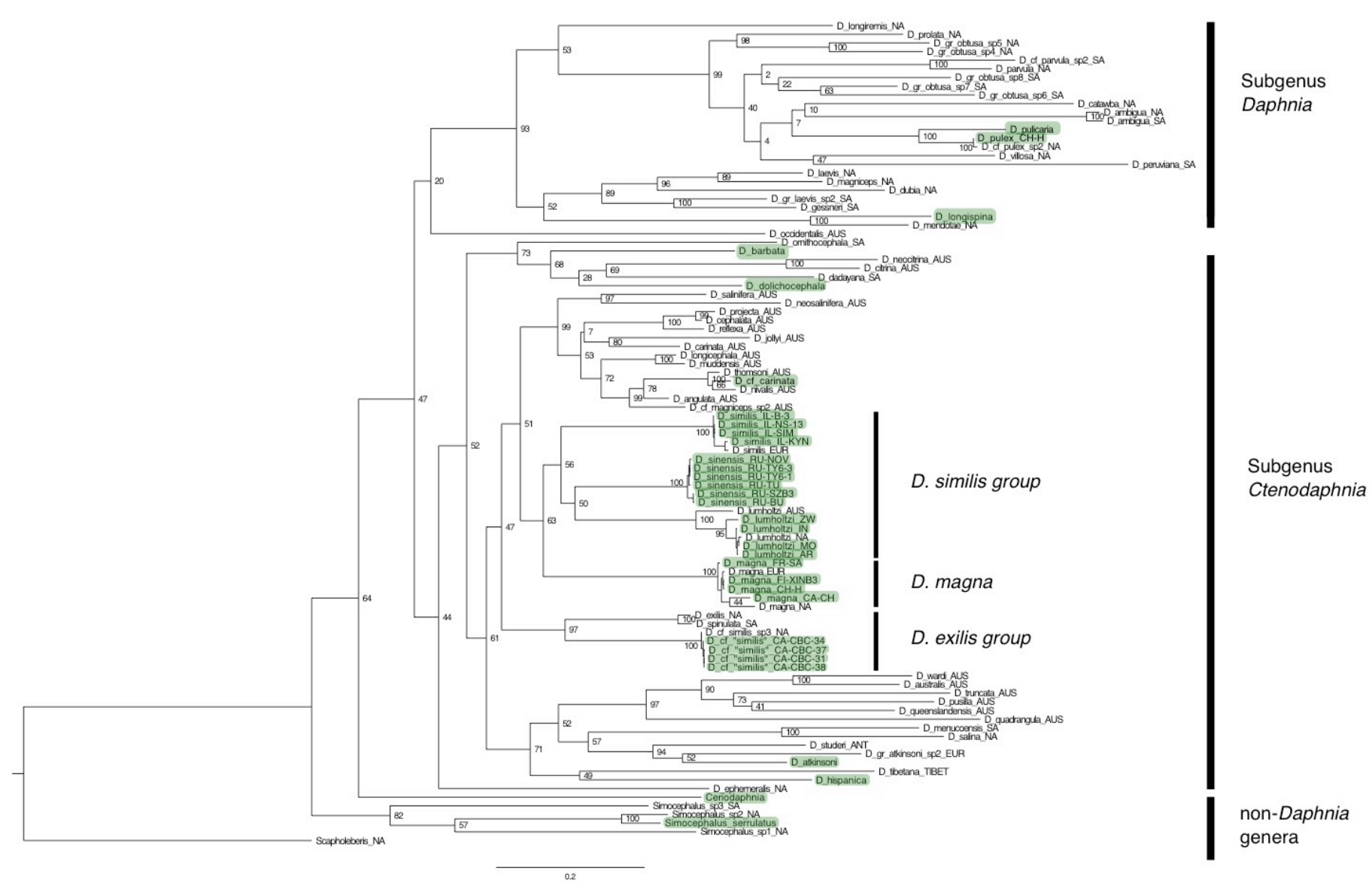


Figure S2. ML tree of the 12S gene including our newly obtained sequences (highlighted in green and named according to column latter taxa, the same labels as in Popova et al., (2016) were used. Where applicable, we provided additional labeling for species groups.

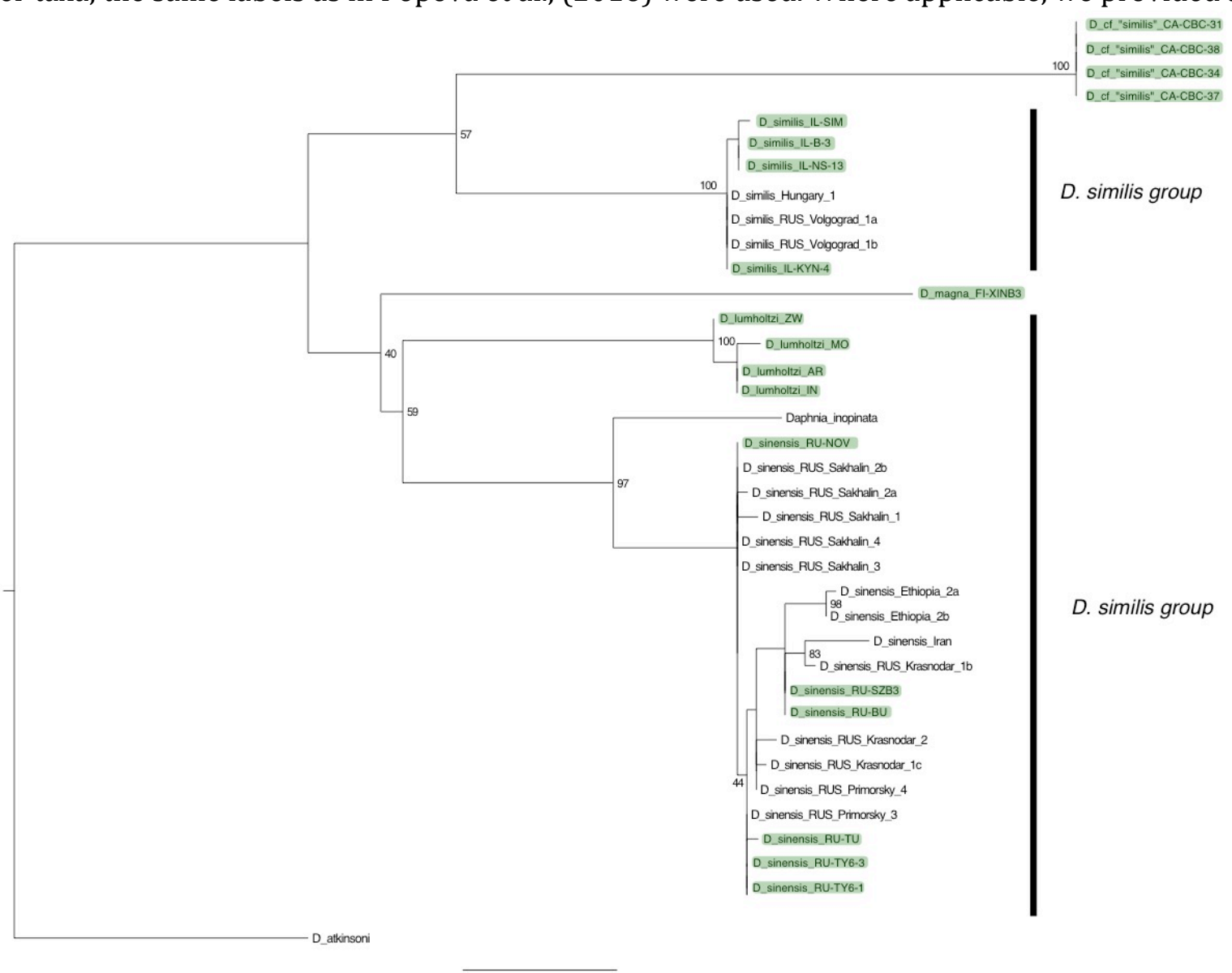


Figure S3. ML tree of the COI gene including our newly obtained sequences (highlighted in green and named according to column

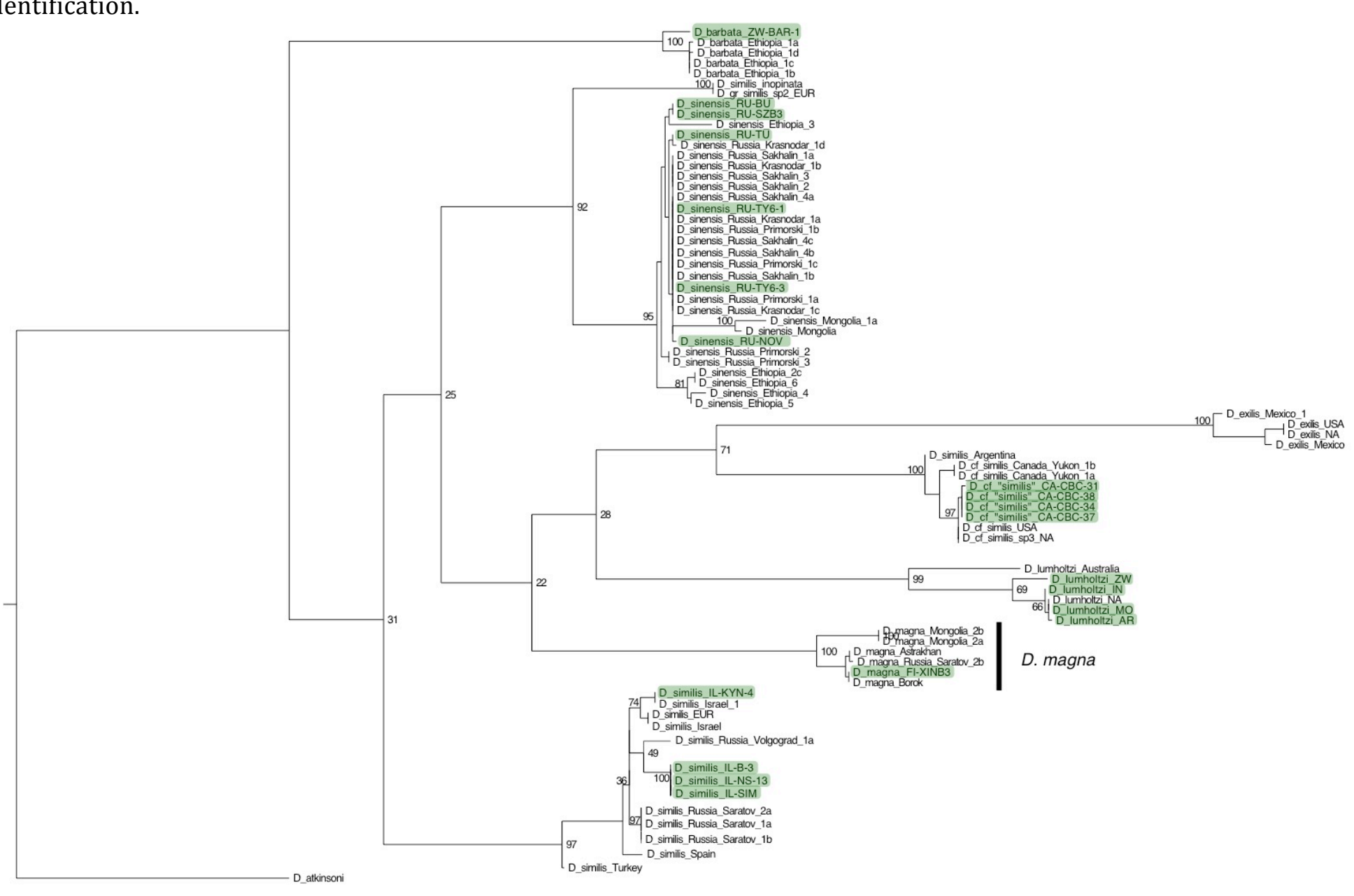


Figure S4. Resume of the BUSCO genome assessment for each of the draft nuclear genome assembly analyzed in this study

\section{BUSCO Assessment Results}

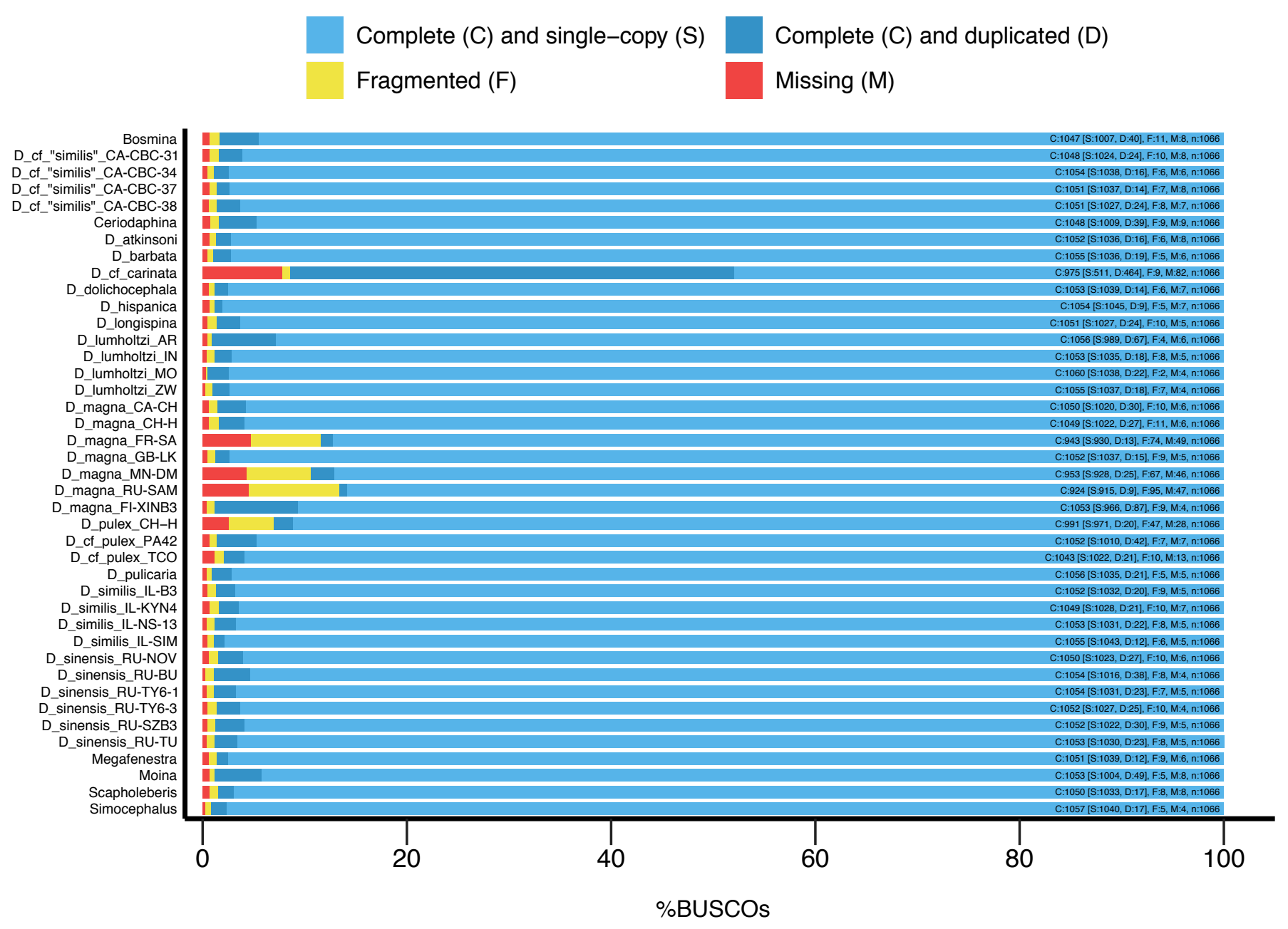


Figure S5. ML amino acid tree of the 636 nuclear genes. Bootstrap values from the RAxML analysis are reported above the nodes and local posterior probability values from the ASTRAL analyses are reported below the nodes. The ASTRAL species trees obtained with nucleotide and amino acid sequences were identical and in complete agreement with the ML topology resulting from the concatenated amino acid dataset. Local posterior probabilities obtained with nucleotide and amino acid sequences are reported on the left and on the right of "/", respectively.

(262

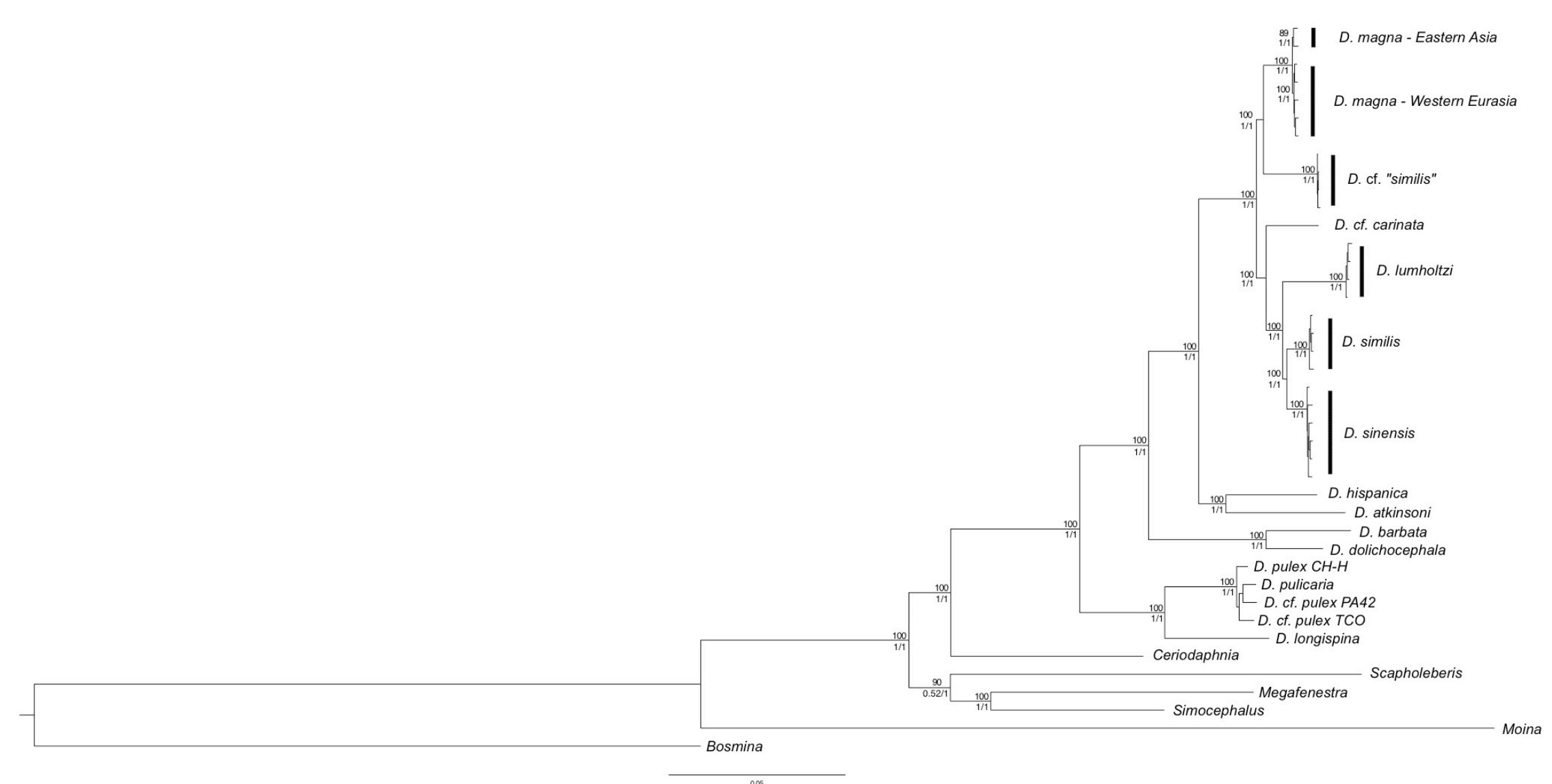


1265 Table S1. Assembly statistics for each of the draft nuclear genome analyzed in this study.

\begin{tabular}{|c|}
\hline Species/Clone name \\
\hline Bosmina cf. longispina maritima (B. corego \\
\hline Moina brachiata (M. brachiata group) \\
\hline Megafenestra aurita \\
\hline Scapholeberis mucronata (S. mucronata gr \\
\hline Simocephalus cf. serrulatus (S. serrulatus gr \\
\hline Ceriodaphina cf. reticulata (C. reticulata gr \\
\hline D. cf. carinata (D. carinata group) \\
\hline D. $c f$ "similis" CA-CBC-31 (D. exilis group) \\
\hline D. $c f$ "similis" CA-CBC-34 (D. exilis group) \\
\hline D. $c f$ "similis" CA-CBC-37 (D. exilis group) \\
\hline D. $c f$ "similis" CA-CBC-38 (D. exilis group) \\
\hline D. atkinsoni (D. atkinsoni group) \\
\hline D. barbata \\
\hline D. dolichocephala \\
\hline D. hispanica \\
\hline D. lumholtzi IN-PA (D. similis group) \\
\hline D. lumholtzi US-AR (D. similis group) \\
\hline D. lumholtzi US-MO (D. similis group) \\
\hline D. lumholtzi ZW-LUM (D. similis group) \\
\hline D. magna $\mathrm{CA}-\mathrm{CH}$ \\
\hline D. magna $\mathrm{CH}-\mathrm{H}$ \\
\hline D. magna FI-XINB3 \\
\hline D. magna FR-SA \\
\hline D. magna GB-LK \\
\hline D. magna $\mathrm{MN}-\mathrm{DM}$ \\
\hline
\end{tabular}

\begin{tabular}{cccc} 
n of scaffold & $\begin{array}{c}\text { N50 } \\
\text { (bp) }\end{array}$ & $\begin{array}{c}\text { max scaffold length } \\
\text { (bp) }\end{array}$ & $\begin{array}{c}\text { total assembly length } \\
\text { (Mb) }\end{array}$ \\
\hline 28611 & 37861 & 699777 & 117 \\
14987 & 55219 & 736482 & 95 \\
21309 & 104119 & 645684 & 112 \\
14674 & 114421 & 976602 & 102 \\
11681 & 67033 & 555441 & 116 \\
34395 & 42048 & 432353 & 158 \\
17888 & 35689 & 311621 & 145 \\
31704 & 26721 & 286429 & 141 \\
28224 & 27013 & 250664 & 133 \\
27942 & 38342 & 299536 & 140 \\
24715 & 30758 & 263925 & 136 \\
15412 & 69719 & 557213 & 122 \\
12651 & 131556 & 856311 & 93 \\
8411 & 133388 & 697702 & 86 \\
27804 & 33690 & 293516 & 119 \\
10906 & 95234 & 514921 & 101 \\
8848 & 77377 & 504408 & 101 \\
8933 & 90651 & 615127 & 102 \\
7787 & 68032 & 950526 & 104 \\
17964 & 31682 & 270834 & 129 \\
24385 & 31607 & 334948 & 135 \\
7664 & 97873 & 2758015 & 198 \\
110666 & 1933 & 282211 & 118 \\
17593 & 37549 & 285667 & 126 \\
114151 & 2094 & 448582 &
\end{tabular}


D. magna RU-SAM

D. similis IL-B3 (D. similis group)

D. similis IL-KNY4 (D. similis group)

D. similis IL-NIZ1-3 (D. similis group)

D. similis IL-SIM-A20-Inb3 (D. similis group)

D. sinensis RU-BU1-3 (D. similis group)

D. sinensis RU-NOV1-01 (D. similis group)

D. sinensis RU-SZB3-2 (D. similis group)

D. sinensis RU-TU2-01 (D. similis group)

D. sinensis RU-TY6-1 (D. similis group)

D. sinensis RU-TY6-3 (D. similis group)

D. pulex $\mathrm{CH}-\mathrm{H}$ (D. pulex group)

D. cf. pulex PA42 (D. pulex group)

D. cf. pulex TCO (D. pulex group)

D. pulicaria (D. pulex group)

D. longispina (D. longispina group)

$\begin{array}{cccc}102897 & 1937 & 47969 & 107 \\ 17988 & 35365 & 362957 & 121 \\ 18626 & 35174 & 339006 & 121 \\ 15467 & 43679 & 551099 & 122 \\ 8924 & 54196 & 401850 & 114 \\ 14078 & 58175 & 378024 & 111 \\ 12893 & 83404 & 564333 & 110 \\ 15095 & 63345 & 381309 & 112 \\ 13596 & 78738 & 637228 & 110 \\ 14908 & 71172 & 378283 & 112 \\ 16245 & 71751 & 470531 & 110 \\ 93853 & 2666 & 77224 & 121 \\ 1822 & 482705 & 1637002 & 143 \\ 5186 & 758069 & 4058679 & 159 \\ 20796 & 44347 & 390586 & 159 \\ 7743 & 73962 & 436802 & \end{array}$

1267

1268 
1269 Table S2. K-score comparison of single mtDNA trees with the best ML nuclear phylogeny.

1270

$\begin{array}{lrr}\text { mtDNA gene } & \text { K-score } & \text { Scale_factor } \\ \text { 12S } & 0.40209 & 0.49948 \\ \text { 16S } & 0.4093 & 0.48842 \\ \text { nad6 } & 0.43029 & 0.16749 \\ \text { nad4 } & 0.44089 & 0.25296 \\ \text { nad5 } & 0.47433 & 0.25396 \\ \text { nad3 } & 0.4797 & 0.23168 \\ \text { nad2 } & 0.49619 & 0.19232 \\ \text { cox2 } & 0.51177 & 0.17958 \\ \text { nad1 } & 0.53062 & 0.26107 \\ \text { nad41 } & 0.54355 & 0.24242 \\ \text { cytb } & 0.56105 & 0.16669 \\ \text { atp6 } & 0.57556 & 0.28293 \\ \text { cox1 } & 0.60351 & 0.85781 \\ \text { cox3 } & 0.60361 & 0.37814 \\ \text { atp8 } & 0.66847 & 0.2097\end{array}$


Table S3. MtDNA substitution rates for each gene, when the prior on the root was placed during the Late Jurassic.

1275

median substitution
mate (per nucleotide $\quad$ 95\% HPD Interval

\begin{tabular}{ccc} 
& per year) & \\
\hline $12 \mathrm{~S}$ & $2.36 \mathrm{E}-09$ & {$[2.1371 \mathrm{E}-09,2.5783 \mathrm{E}-09]$} \\
$16 \mathrm{~S}$ & $2.75 \mathrm{E}-09$ & {$[2.5514 \mathrm{E}-09,2.9517 \mathrm{E}-09]$} \\
atp6 & $3.81 \mathrm{E}-09$ & {$[3.3984 \mathrm{E}-09,4.1797 \mathrm{E}-09]$} \\
atp8 & $6.18 \mathrm{E}-09$ & {$[5.0053 \mathrm{E}-09,7.4255 \mathrm{E}-09]$} \\
cox1 & $3.29 \mathrm{E}-09$ & {$[3.0757 \mathrm{E}-09,3.5226 \mathrm{E}-09]$} \\
cox2 & $3.04 \mathrm{E}-09$ & {$[2.7471 \mathrm{E}-09,3.3334 \mathrm{E}-09]$} \\
cox3 & $3.36 \mathrm{E}-09$ & {$[3.0847 \mathrm{E}-09,3.6826 \mathrm{E}-09]$} \\
cytb & $3.45 \mathrm{E}-09$ & {$[3.1607 \mathrm{E}-09,3.7103 \mathrm{E}-09]$} \\
nad1 & $4.48 \mathrm{E}-09$ & {$[4.1026 \mathrm{E}-09,4.8607 \mathrm{E}-09]$} \\
nad2 & $5.30 \mathrm{E}-09$ & {$[4.9365 \mathrm{E}-09,5.7036 \mathrm{E}-09]$} \\
nad3 & $4.14 \mathrm{E}-09$ & {$[3.6142 \mathrm{E}-09,4.687 \mathrm{E}-09]$} \\
nad4 & $4.97 \mathrm{E}-09$ & {$[4.6486 \mathrm{E}-09,5.309 \mathrm{E}-09]$} \\
nad4_l & $4.36 \mathrm{E}-09$ & {$[3.7827 \mathrm{E}-09,4.9859 \mathrm{E}-09]$} \\
nad5 & $4.58 \mathrm{E}-09$ & {$[4.2862 \mathrm{E}-09,4.8585 \mathrm{E}-09]$} \\
nad6 & $5.78 \mathrm{E}-09$ & {$[5.2166 \mathrm{E}-09,6.3765 \mathrm{E}-09]$}
\end{tabular}


1278

1279

1280

1281

Table S4. MtDNA substitution rates for each gene, when the prior on the root was placed during the Early Jurassic.

\section{median substitution}

mtDNA gene rate (per nucleotide

95\% HPD Interval per year)

$\begin{array}{ccc}12 \mathrm{~S} & 2.14 \mathrm{E}-09 & {[1.9449 \mathrm{E}-09,2.3487 \mathrm{E}-09]} \\ 16 \mathrm{~S} & 2.49 \mathrm{E}-09 & {[2.3049 \mathrm{E}-09,2.6662 \mathrm{E}-09]} \\ \text { atp6 } & 3.48 \mathrm{E}-09 & {[3.133 \mathrm{E}-09,3.8325 \mathrm{E}-09]} \\ \text { atp8 } & 5.68 \mathrm{E}-09 & {[4.569 \mathrm{E}-09,6.8037 \mathrm{E}-09]} \\ \text { cox1 } & 3.00 \mathrm{E}-09 & {[2.7977 \mathrm{E}-09,3.2306 \mathrm{E}-09]} \\ \text { cox2 } & 2.76 \mathrm{E}-09 & {[2.4792 \mathrm{E}-09,3.0282 \mathrm{E}-09]} \\ \text { cox3 } & 3.05 \mathrm{E}-09 & {[2.7789 \mathrm{E}-09,3.3219 \mathrm{E}-09]} \\ \text { cytb } & 3.14 \mathrm{E}-09 & {[2.8887 \mathrm{E}-09,3.395 \mathrm{E}-09]} \\ \text { nad1 } & 4.10 \mathrm{E}-09 & {[3.757 \mathrm{E}-09,4.4552 \mathrm{E}-09]} \\ \text { nad2 } & 4.85 \mathrm{E}-09 & {[4.4891 \mathrm{E}-09,5.1952 \mathrm{E}-09]} \\ \text { nad3 } & 3.78 \mathrm{E}-09 & {[3.3261 \mathrm{E}-09,4.3197 \mathrm{E}-09]} \\ \text { nad4 } & 4.53 \mathrm{E}-09 & {[4.2119 \mathrm{E}-09,4.8255 \mathrm{E}-09]} \\ \text { nad4_l } & 3.98 \mathrm{E}-09 & {[3.4513 \mathrm{E}-09,4.5235 \mathrm{E}-09]} \\ \text { nad5 } & 4.17 \mathrm{E}-09 & {[3.9123 \mathrm{E}-09,4.4284 \mathrm{E}-09]} \\ \text { nad6 } & 5.28 \mathrm{E}-09 & {[4.7482 \mathrm{E}-09,5.8042 \mathrm{E}-09]}\end{array}$


Table S5. MtDNA substitution rates for each gene, when the prior on the root was placed during the Permian.

1283

median substitution
matDN gene (per nucleotide per year)

\begin{tabular}{ccc} 
& per year) & \\
\hline $12 \mathrm{~S}$ & $1.74 \mathrm{E}-09$ & {$[1.5611 \mathrm{E}-09,1.9368 \mathrm{E}-09]$} \\
$16 \mathrm{~S}$ & $2.03 \mathrm{E}-09$ & {$[1.8591 \mathrm{E}-09,2.2142 \mathrm{E}-09]$} \\
atp6 & $2.84 \mathrm{E}-09$ & {$[2.5299 \mathrm{E}-09,3.1799 \mathrm{E}-09]$} \\
atp8 & $4.63 \mathrm{E}-09$ & {$[3.7722 \mathrm{E}-09,5.6958 \mathrm{E}-09]$} \\
cox1 & $2.45 \mathrm{E}-09$ & {$[2.2373 \mathrm{E}-09,2.6665 \mathrm{E}-09]$} \\
cox2 & $2.25 \mathrm{E}-09$ & {$[2.0155 \mathrm{E}-09,2.5125 \mathrm{E}-09]$} \\
cox3 & $2.49 \mathrm{E}-09$ & {$[2.2410 \mathrm{E}-09,2.7598 \mathrm{E}-09]$} \\
cytb & $2.56 \mathrm{E}-09$ & {$[2.3273 \mathrm{E}-09,2.8148 \mathrm{E}-09]$} \\
nad1 & $3.35 \mathrm{E}-09$ & {$[3.0131 \mathrm{E}-09,3.6892 \mathrm{E}-09]$} \\
nad2 & $3.96 \mathrm{E}-09$ & {$[3.6097 \mathrm{E}-09,4.3268 \mathrm{E}-09]$} \\
nad3 & $3.09 \mathrm{E}-09$ & {$[2.6615 \mathrm{E}-09,3.5333 \mathrm{E}-09]$} \\
nad4 & $3.71 \mathrm{E}-09$ & {$[3.3981 \mathrm{E}-09,4.0291 \mathrm{E}-09]$} \\
nad4_l & $3.25 \mathrm{E}-09$ & {$[2.8016 \mathrm{E}-09,3.7404 \mathrm{E}-09]$} \\
nad5 & $3.41 \mathrm{E}-09$ & {$[3.1382 \mathrm{E}-09,3.6915 \mathrm{E}-09]$} \\
nad6 & $4.32 \mathrm{E}-09$ & {$[3.8607 \mathrm{E}-09,4.8379 \mathrm{E}-09]$}
\end{tabular}

